\title{
AN UPDATED CHRONOLOGY FOR THE NORTHERN UBAID AND LATE GHALCOLITHIC PERIODS IN SYRIA : NEW EVIDENCE FROM TELL HAMMAM ET-TURKMAN
}

\author{
By PETER M. M. G. AKKERMANS
}

\subsection{Introduction}

The present article concerns the Northern Ubaid and Late Chalcolithic periods in Syria and northern Mesopotamia and presents an updated chronological framework for both periods, ${ }^{1}$ mainly based on recent excavations at the large site of Tell Hammam et-Turkman on the Balikh. Tell Hammam et-Turkman is a huge mound, measuring $500 \times 450 \times 45 \mathrm{~m}$, and is located about $75 \mathrm{~km}$ north of the modern town of Raqqa, on the east bank of the river Balikh, northern Syria (Fig. 1). Since 1981 the University of Amsterdam has carried out excavations (Van Loon 1982, 1983, 1985 ; Van Loon and Meijer 1983) which have given ample evidence of the importance of the site during the 3rd and 2nd millennia в.c., but test trenches on the east slope of the tell indicate that already during prehistoric times Tell Hammam et-Turkman was an impressive mound. Northern Ubaid-related levels comprise an accumulation of almost $15 \mathrm{~m}$ of occupational debris, immediately followed by Late Chalcolithic layers, which reach a thickness of about $10 \mathrm{~m}$. At present, the prehistoric mound is almost completely buried underneath an extensive overburden of later occupational remains.

Here I confine myself exclusively to the results of the trenches on the east slope of Tell Hammam et-Turkman. A series of trenches $2 \mathrm{~m}$ wide was laid out, to be excavated in a number of steps. These narrow trenches perfectly met our aim, which was to set up a stratigraphy and pottery sequence at the site. The chronological positioning of the ceramics is based on the delineation of continuity and change in vessel shape, techniques of pottery manufacture and pottery decoration. It is important to stress the continuous and uninterrupted local development of the prehistoric ceramic sequence at Tell Hammam et-Turkman.

\subsection{Chronology and comparisons}

Two main periods are distinguished, mainly based on ceramic evidence but supported by additional information from other kinds of artifacts: a Northern Ubaid-related period, termed Hammam IV, and a Late Chalcolithic period, termed Hammam V. ${ }^{2}$ The basic analytical unit within each period is the stratum, defined on the basis of observations on stratigraphical deposition by construction, occupation or erosion. Each stratum yielded a coherent body of pottery. On typological grounds, primarily based on rim, vessel and decoration typology, but closely supported by technological developments in pottery production, these strata

\footnotetext{
This report was completed in December 1986.

${ }^{2}$ During excavations at Tell Hammam et-Turkman and at the adjacent site of Tell Damishliyya, ten main periods, indicated by Roman numerals, were distinguished:
}

I: Pre-Pottery Neolithic; II: Pottery Neolithic; III: Halaf; IV : Ubaid; V: Late Chalcolithic; VI: Early Bronze; VII: Middle Bronze; VIII: Late Bronze; IX: Iron Age; X: Parthian/Roman. 
were regrouped into phases. These phases emphasize long-term trends in ceramic complexes.

Twelve strata, regrouped into 4 phases, were distinguished in period IV, whereas 7 strata, regrouped into 2 phases were ascribed to period $\mathrm{V} \cdot{ }^{3}$ A detailed account of the internal ceramic chronology at Tell Hammam et-Turkman and an extensive discussion of the various types of pottery ${ }^{4}$ found at the site has been given elsewhere. ${ }^{5}$ Here I focus on the importance of the site for comparative chronology. I shall attempt to relate the sequence from Tell Hammam et-Turkman to those from other sites in neighbouring regions, thus compiling a refined chronological scheme for the late 5th and 4th millennium B.c. in Syria.

The chronological framework presented here is based on three lines of evidence :

1) rim and decoration typology (embedded within the stratigraphic sequence)

2) pottery technology

3) radiocarbon dates

The combination of these types of chronological information yields a detailed local chronology and provides a secure basis for cross-dating with other sites.

\section{Relative chronology : the typological development}

\subsection{Hammam IV}

At present, only few excavations within the northern fringes of the Ubaid tradition have yielded Northern Ubaid ceramics in a stratigraphical context. In northern Iraq large quantities of Ubaid ceramics were found at Tepe Gawra, Arpachiyah and Telul eth-Thalathat. The first seems to be the most important, providing a lengthy sequence of Northern Ubaid pottery. The chronological positioning of the pottery from Arpachiyah and Telul eth-Thalathat is less clear, due to the nature of the excavated material and of the excavations themselves. At Arpachiyah all the published Ubaid ceramics stem from the cemetery, although occupational remains were also excavated (TT 1-4; Mallowan and Rose 1935: 70). At Telul ethThalathat the chronological correlation between the pottery from the Ubaid strata excavated in various trenches by different teams is not clear (cf. Egami 1959; Fukai et al. 1970). Northern Ubaid pottery found during recent excavations at Tell Leilan, located in the upper Khabur region of northeastern Syria, shows close affinities with that found at the northern Iraqi sites (Schwartz 1982). In many respects the upper Khabur area is closely orientated towards northern Iraq. Ubaid-related wares were also found in excavations in western Syria and southeastern Anatolia, e.g. in the Amuq plain (Braidwood and Braidwood 1960 ; see also Watson 1965), Hama (Fugmann 1958) and Ras Shamra (Courtois 1962). In Anatolia Ubaid-like pottery was found at places like Tarsus (Goldman 1956), Mersin (Garstang 1953) and Sakçe Gözü (du Plat Taylor et al. 1950).

\footnotetext{
${ }^{3}$ From a stratigraphical point of view, the actual number of strata is larger. In period IV, after stratum 12 , two more strata ( 13 and 14 ) were present before the beginning of the Late Chalcolithic period, and in period V, after stratum 3, stratum 4 was distinguished. However, these strata did not yield any useful pottery and were thus excluded from further ceramic analysis. Stratum 1 in period IV is reserved for the until now unexcavated occupational remains, $c a .1 \mathrm{~m}$ thick, of
}

which the presence below the "stratum 2" level was established by drilling.

"A "type" is defined by the combination of both rim shape and vessel shape. Generally, a particular rim shape is associated with a particular vessel shape (i.e. bowl, pot or jar).

${ }^{5}$ P.M.M.G. Akkermans, in press. The present article is based on these papers. 


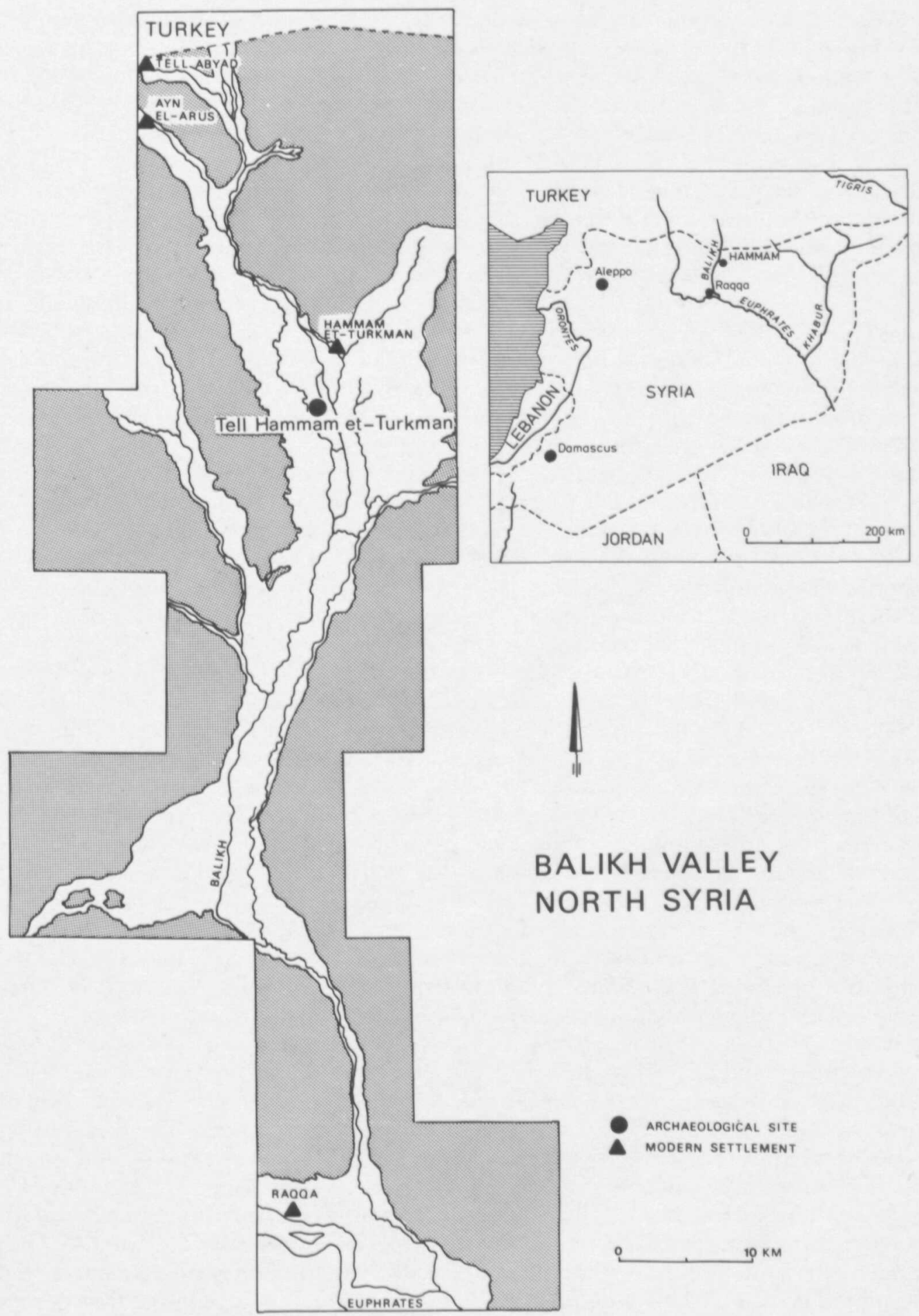

Fig. 1. Map of the Balikh Valley with (inset) its location in Syria. 
When discussing the Ubaid-related period IV ceramics of Tell Hammam etTurkman it is important to distinguish between painted and unpainted wares. Throughout the ceramic sequence painted wares always constituted a minority. In Hammam IV A, the earliest period IV ceramic phase recognized, only $17.6 \%$ of the pottery was painted and in the succeeding phases this percentage was reduced to $13.6 \%$ in Hammam IV B, $6 \%$ in Hammam IV C and 2.4\% in Hammam IV D. A first glance at the Period IV pottery seems to indicate a close relationship between Hammam IV ceramics and those of the "type sites" of the Northern Ubaid ceramic tradition in northern Iraq. A closer look, however, will reveal that this resemblance is only true for the painted wares. Both in shape and design comparisons can be found between the Hammam IV painted pottery and that of the Northern Ubaid sites found in the east. The undecorated pottery, however, has only yielded very few comparisons with these northern Iraqi sites. Besides, whereas at Tell Hammam etTurkman undecorated pottery predominates, the reverse is true at the Iraqi sites; here undecorated wares are only found in low numbers. At Tell Hammam etTurkman evidence was found of a well-developed local ceramic tradition, which only adopted external (i.e. Northern Ubaid) elements on a limited scale. This points to the existence of a cultural unity at Tell Hammam et-Turkman, and in the Balikh valley as a whole, strongly protected from foreign influences. In view of the limited influence of Ubaid ceramic traits visible in the Hammam sequence, I prefer to describe the Hammam IV pottery as "Northern Ubaid-related" rather than as true "Northern Ubaid". It is, however, interesting that no painted ware was found other than Ubaid-related ; no traces of an independently developed style of decoration have appeared. Besides, painted ware is virtually limited to small plain-rim bowls. Only a few painted jars or pots were found. A simple Student's t-test (cf. Thomas 1976: $227 \mathrm{ff}$.) indicated a statistically significant difference in diameter and wall thickness between painted and unpainted bowls. Painted bowls showed significantly smaller diameters and thinner walls than their undecorated counterparts. In comparison with undecorated vessels, the production of painted bowls involved the investment of a great amount of extra energy, which will have been reflected in their intrinsic value. Apparently special care was taken in the production of painted vessels, thus suggesting that these vessels fulfilled a particular role or function. Generally, bowls will have been in common use in daily household activities as serving vessels or in food production, thus having a high visibility. In the case of the carefully produced and delicately decorated bowls, emphasis is on their outer appearance, which visualizes the value of the object itself and, ultimately, the capability of its owner to acquire such objects. I suggest that these vessels are statusrelated in the Balikh valley. In a broader perspective, this adoption of Northern Ubaid cultural traits for expressing status within a basically strong locally bound cultural tradition may reflect a core versus periphery relationship. The distribution and formal appearance of Ubaid-related pottery throughout the northern fringe of the fertile crescent indicates a clear regional diversity. Based on the Hammam IV sequence a broad partition of the Northern Ubaid ceramic tradition is possible, with northern Iraq and northeastern Syria on the one hand (the Northern Ubaid homelands) and western Syria and southeastern Anatolia on the other hand (the periphery areas). Tell Hammam et-Turkman is situated in an intermediate region 
between various areas which, despite some affinities, clearly give evidence of different cultural developments. The site shows that Northern Ubaid cultural traits only penetrated into northwestern Syria on a limited scale. Ties between the Northern Ubaid homelands and the outer regions are maintained through the distinctive painted ceramics. The imitation of Northern Ubaid ceramics in the periphery ${ }^{6}$ suggests some form of dependency of these peripheral areas upon the core lands, the nature of which is not yet clear. Local elites may have used Ubaidstyle pottery to express status and thus to emphasize differences in power and social rank.

A date around $4500 / 4400-3600$ B.c. (uncalibrated) is suggested here for the Hammam IV period at Tell Hammam et-Turkman.

\subsubsection{Hammam IV A}

Hammam IV A comprises the pottery found in the earliest strata at Tell Hammam et-Turkman and is characterized by a large variety of pottery types, the vast majority undecorated. Painting is the only technique of decoration used and is limited in application to small, thin-walled bowls and jars. About $17.6 \%$ of Hammam IV A rim sherds were painted. Decoration is marked by intricate, closestyle patterns, which show a large variability in design (Fig. 2). The majority of design elements is limited in temporal distribution to this particular phase. Most common are small flaring or hemispherical plain-rim bowls, the majority of which was painted. To some extent this pottery resembles that of Gawra XIX-XVII, Arpachiyah and Amuq E. In the lower strata at Tepe Gawra bell-shaped bowls appeared, which are marked by a flaring S-shaped profile, by rounded bases and by intricate painting (Tobler 1950: 134-35). At Tell Hammam et-Turkman comparable bell-shaped vessels were found solely in the lower Hammam IV A strata 2 and 3; they were not present in any of the later strata. Simple hemispherical bowls are common both at Tepe Gawra and Tell Hammam et-Turkman. Beside the painted bell-shaped and hemispherical bowls very few resemblances were found between the ceramic assemblages from Gawra XIX-XVII and Hammam IV A. A characteristic late Hammam IV A bowl with sharply incurving vessel wall (Fig. 7: 90-93) can be compared to a rare shape found at Gawra XVIII. At Gawra this type persisted into later strata (Tobler 1950: 135), whereas at Tell Hammam et-Turkman this type is limited to stratum 4.

Close parallels to some of the Hammam IV A pottery types are also found at the Ubaid cemetery of Arpachiyah which, according to its excavators, was only in use during a relatively short period (Mallowan and Rose 1935: 43). On the grounds of stylistic arguments and of the positioning of the various burials, the pottery from the Arpachiyah cemetery was divided into an early and a late period. Mallowan (1970: 398-401) favored a late date for the Ubaid pottery from Arpachiyah on the basis of some close parallels with Eridu 7-6 and Gawra XIII, although some vessels (viz. bell-shaped bowls) point to use of the cemetery at an earlier date. Here we correlate the Ubaid cemetery at Arpachiyah with Gawra XVII-XIII, Leilan VI A-early VI B, Telul eth-Thalathat XIV-XIII and, ultimately, late Hammam IV A-Hammam

\footnotetext{
${ }^{6}$ A waster consisting of several fused painted bowls points to local production of painted pottery. At present

there is no evidence that painted ceramics were acquired by trade or the like.
} 
IV C. Most of the Arpachiyah ceramics are simple plain rim bowls. Few vessels were found with grooved or flattened rims (Mallowan and Rose 1935, Fig. 29: 7), comparable with examples from Leilan VI A (Schwartz 1982, Fig. 52: 1, 3) and Telul eth-Thalathat XIV (Fukai et al. 1970, Pl. LXXI: 26, 27). Bell-shaped bowls appeared in some of the deep graves (Mallowan and Rose 1935, Fig. 29: 1, 2, 4). The bell-shaped bowls and the flat-based bowls with flat or grooved rims indicate an early date for some of the Arpachiyah burials, i.e.Gawra XIX-XVII, Leilan VI A, Telul eth-Thalathat XIV and Hammam IV A. The diagonally slashed pattern indicated by one bowl (Mallowan and Rose 1935, Fig. 30: 3) is a characteristic Leilan VI A design (Schwartz 1982: 271). A comparison in style of decoration between the pottery ascribed to the early and late periods at Arpachiyah respectively reveals a clear difference : whereas the early ceramics are decorated in a busy manner, showing carefully executed designs, the pottery ascribed to the late period is marked by bold, sweeping designs and broad bands of paint. This late pottery from Arpachiyah shows close affinities with Hammam IV C ceramics. Some vessels, viz., beakers (Mallowan and Rose 1935, Fig. 33: 10) and flat-based bowls with bold designs (ibid., Fig. 32: 1-4) indicate a close connection with Gawra XIII, whereas simple hemispherical bowls with sweeping bold designs (ibid., Fig. 31:3-4) compare with Hammam IV B-IV C pottery.

The closest affinities, however, with the Hammam IV A pottery are not found in northern Mesopotamia, but in western Syria, viz., the Amuq plain. In many aspects Hammam IV A ceramics resemble the Amuq E ceramic assemblage. During excavations at Tell Kurdu large quantities of locally produced, Ubaid-related monochrome painted pottery were recovered. Most of the intricate, closely knit Hammam IV A designs are found within this Amuq E assemblage. Besides similarities in design, close parallels also exist in vessel shape. Bead-rim vessels are found at Tell Hammam et-Turkman and in the Amuq. A characteristic Hammam IV A bead-rim pot (Fig. 7: 95, 96) may correlate with the "New Cooking Pot Ware" of the Amuq (cf. Braidwood and Braidwood 1960: 78). Bead rims probably constitute a basically west Syrian ceramic trait. In northeastern Syria and northern Iraq bead-rims appear in small numbers in the later stages of the Northern Ubaid period (Leilan VI B ; Schwartz 1982, Fig. 54). Other parallels between Hammam IV A and Amuq E are found in simple plain-rim bowls and in a class of bowls with sharply inturning rims (Fig. 7: 105, 106) which at Tell Hammam et-Turkman are a characteristic early shape but are considered to represent an "abnormal" rim profile in the Amuq (Braidwood and Braidwood 1960: 188).

It should be stressed that Amuq E ceramics only correlate with Hammam IV A pottery. None of the characteristic vessel shapes and designs of the later Hammam IV ceramic phases were found at Tell Kurdu, which indicates a considerable hiatus in the Amuq sequence. Such a gap was already suggested by the Braidwoods when discussing the pottery from Karaca Khirbet 'Ali (Braidwood and Braidwood 1960: 201-204). At this site Ubaid-like painted pottery was found which did not fit within the Amuq E assemblage. Comparisons with Tell Hammam et-Turkman suggest that the Karaca Khirbet 'Ali sherds are contemporary with Hammam IV C ceramics. The Amuq $\mathrm{F}$ pottery which until now was placed directly above the Amuq E pottery in chronological terms, shows but little resemblance to the preceding pottery 
tradition (ibid.: 226). The Amuq F ceramics correlate with Hammam V B pottery, which points to a time gap of about 800 years between Amuq phases E and F.

\subsubsection{Hammam IV B}

During the Hammam IV A phase the ties between Tell Hammam et-Turkman and the eastern sites (northeastern Syria-northern Iraq) were not strongly developed. At the time of Hammam IV B, the affinities with the east become even weaker. Comparisons are merely found in the motifs used in decoration, not in vessel shape.

The Hammam IV B pottery compares with Gawra XVI-XV, Leilan VI A and Telul eth-Thalathat XIV-XIII. The Hammam IV B painted ware is marked by bold, sweeping designs, which are often rather coarsely executed (cf. Fig. 4). The Hammam IV B style of painting is readily distinguishable from that of the lower, Hammam IV A strata. Some new designs were introduced in Hammam IV B, e.g. the broad pendent zigzags (Fig. 4: 43) or solidly painted pendent semi-circles in combination with an undulating line (Fig. 4: 40, 44, 46). At Tepe Gawra some of these designs already appeared in stratum XVII (Tobler 1950, Pl. LXXIV: b.13). At Gawra, an important early motif which persisted into the Gawra XVI-XV strata is represented by the "ladder" pattern (ibid.: 138). At Tell Hammam et-Turkman this design is found in phase IV A only (cf. Fig. 2: 1). When compared with those of the early Gawra strata, the painted ceramics found in Gawra strata XVI-XV indicate a reduction in shape and design variability, although in technical aspects this pottery closely equals the ceramics of the lower strata (Tobler 1950: 138). Bellshaped bowls are no longer found at Tepe Gawra. The most common bowl shape at Tepe Gawra is a closed vessel, marked by a contracted rim forming a slightly sloping shoulder (ibid.: 138 and Pl. CXXIV: 127, 129-131, 133, 134). This shape is very rare at Tell Hammam et-Turkman, where open and flaring or straight-walled vessels predominate. At Gawra XVI-XV open bowls seem to be uncommon (ibid.: 139). The only new type introduced in Gawra XVI-XV is a cup-like vessel characterized by a rather pointed base and a contracting rim (ibid.: 139). These cups are either undecorated or rather simply painted. The exterior of some of these cups is solidly painted, a design which at Tell Hammam et-Turkman appears for the first time in Hammam IV B. At Tell Hammam et-Turkman a cup-like vessel was also introduced in Hammam IV B (Fig. 4: 41-43), although a predecessor was found in Hammam IV A. These cup-like vessels or goblets are not found at Tepe Gawra.

The Ubaid pottery from Telul eth-Thalathat is related to Gawra XVII-XV and particularly to Gawra XIII ceramics. The closest parallels between Telul ethThalathat and Tell Hammam et-Turkman are found in Hammam IV C, but Hammam IV B and perhaps the end of Hammam IV A may already be correlated with stratum XIV of Telul eth-Thalathat.

During the 1956-57 soundings at Telul eth-Thalathat Ubaid material was recorded in trenches $\mathrm{M}$ and IX (Egami 1959). The pottery found in trench $\mathrm{M}$ was divided into three groups, termed I (subdivided into a and b), II and III. In trench IX twelve strata were recognized (XII-I) ; the pottery from XII to VIIb is ascribed to the Ubaid period. The 1964 excavations at Telul eth-Thalathat extended the sequence of trench IX further downward and two Ubaid strata (XIV-XIII) were 
added to the known sequence (Fukai et al.1970). According to its excavators, stratum XIV in trench IX corresponds to Ubaid Ia in trench $\mathrm{M}$, whereas Ib is tentatively placed between strata XIV and XIII (ibid.: 41). Comparisons with Tell Hammam et-Turkman partly confirm this temporal assignment; Ia at Telul ethThalathat yielded comparisons with Hammam IV A, whereas Ib indicated close resemblances to Hammam IV B. However, stratum XIV at Telul eth-Thalathat compares both with Hammam IV A and IV B, and thus with Ubaid Ia-Ib in trench $\mathrm{M}$ of Telul eth-Thalathat (see chronological table, Fig. 11). Generally, at Telul ethThalathat XIV-XIII the emphasis in style of decoration is on simple open and sweeping design configurations comparable with Hammam IV B-IV C. Ladders are found in the stratum XIV pottery of Telul eth-Thalathat (Fukai et al. 1970, Pl. LXXVII: 14, 15). At Tepe Gawra the ladder motif is mainly found in the early strata XIX-XVII, but is still present in the subsequent strata XVI-XV, where it is considered to be an important "survival" of earlier times (Tobler 1950: 138). At Tell Hammam et-Turkman the ladder motif is limited to Hammam IV A. Other designs found at Telul eth-Thalathat, e.g. solidly painted exteriors or pendent semi-circles, are first introduced at Tell Hammam et-Turkman in phase IV B. In stratum XIV at Telul eth-Thalathat some closed vessels with inverted rims appeared (Fukai $e t$ al. 1970, PI. LXXVII: 5, 6), which correlate with Gawra XVII (Tobler 1950, Pl. CXXI: 100) and Leilan VI A (Schwartz 1982, Fig. 52: 4, 6, 8). At Tell Hammam etTurkman this type of pottery was found only in the last Hammam IV A stratum (cf. Fig. 7: 90-92). Bell-shaped bowls are reported to be present in stratum XIV and, particularly, stratum XIII at Telul eth-Thalathat (Fukai et al. 1970: 34, 40), but these vessels are definitely different, both in shape and decoration, from Gawra XIX-XVII, Arpachiyah or Hammam IV A bell-shaped vessels. At these sites, the term "bell-shaped bowl" refers to a class of thin-walled, flaring bowls with a slightly $\mathrm{S}$-shaped profile, rounded base and intricate decoration. Since these vessels are a characteristic early Northern Ubaid ceramic trait, an inflationary use of the term "bell-shaped bowl" must be avoided.

Leilan VI A is compared with Gawra XVII-XVI (Schwartz 1982: 271). Leilan VI A pottery is marked by diagonally slashed and undulating line motifs on open flat or pinched rim shapes. Closed vessels with inverted lips are also characteristic (ibid.: 271). At Tell Hammam et-Turkman, undulating lines are a common design throughout the Hammam IV period, but vertical or diagonal slashes between horizontal lines are virtually limited to Hammam IV A (cf. Fig. 2: 2, 14). Only very few examples were found in Hammam IV B. The Leilan VI A flat rims are absent at Tell Hammam et-Turkman, whereas the closed vessels with inverted rims are limited to the last stratum of Hammam IV A. Thus, the Leilan VI A ceramics correlate with the later part of Hammam IV A. Schwartz (1982: 259), however, also notices clear parallels with Gawra XV-XIV and Telul eth-Thalathat XIV-XIII, which suggest a chronological correlation with Hammam IV B.

\subsubsection{Hammam IV C}

In Hammam IV $\mathrm{C}$ there are considerable alterations in shape and vessel decoration, and in techniques of pottery manufacture. Hammam IV C represents a period of innovative developments in pottery production, although in many aspects 
Hammam IV C pottery resembles the preceding Hammam IV B ceramics. Here, Hammam IV C is correlated with Gawra XIII, Leilan VI B, Telul eth-Thalathat XIII and the late graves at the Arpachiyah cemetery.

At Tell Hammam et-Turkman, the phase IV C assemblage is readily distinguished from that of the earlier phases. Some important alterations took place in tempering and firing techniques (see section 3.3.). At the same time, there is a sharp decrease in decorated pottery. The emphasis is on widely executed designs, consisting of broad lines covering the larger part of a vessel (Fig. 5). Although the designs resemble the sweepingly executed Hammam IV B motifs, the Hammam IV C painted ware in general suggests more carefully executed painting. Decoration changes are accompanied by important changes in vessel shape. Generally, vessels become large, showing wide diameters and thick walls. The closest parallels between Hammam IV C ceramics and those of the eastern (i.e. northern Mesopotamian) sites are found in simple, deep hemispherical bowls (e.g. Fig. 5: 57, 58). In Hammam IV $\mathrm{C}$ large, round-based bowls, decorated in a simple manner (e.g. undulating lines or solid black areas), are common (Fig. 5). Both in shape and decoration these bowls resemble vessel forms at Gawra XIII (Tobler 1950, Pl. CXXVIII: 192) or Telul eth-Thalathat XIII (Fukai et al. 1970, Pl. LXXI: 12,14,18). A new closed bowl type, marked by an interior beveled rim (Fig. 5: 55), is related to shapes in Gawra XIII (Tobler 1950, Pl. CXXVII: 172) and Leilan VI B (Schwartz 1982, Fig. 47: 2). In Hammam IV C a jar fragment with a flaring, beaked rim was found (Fig. 5: 70). At Tell Hammam et-Turkman this type is very rare, but at Tepe Gawra it was the principal jar shape in the strata XVI-XV (Tobler 1950: 143). An example was also found in Gawra XIII (ibid.: 143). The characteristic Gawra XIII beakers (ibid.: 142 and Pl. CXXIX-CXXX: 195-209), which were also found at Telul ethThalathat XIII (Fukai et al. 1970, Pl. LXXI: 19) and Leilan VI B (Schwartz 1982, Fig. 47: 3, 5), are absent at Tell Hammam et-Turkman. New in Hammam IV C is a group of usually very wide, flaring bowls with probably flat bases (Fig. 7: 110-112). The vast majority of these vessels is undecorated. These large bowls may be related to the very wide, straight-sided and flat-based bowls which are rather common in the late burials at the Arpachiyah cemetery (Mallowan and Rose 1935: 46). Similar vessels were found in Gawra XIII (Tobler 1950, Pl. CXXVII: 179), Telul ethThalathat XIII (Fukai et al. 1970, Pl. LXXI: 1-11) and Leilan VI B (Schwartz 1982, Fig. 50: 6). At Tell Hammam et-Turkman very few incised sherds were found in phase IV C. In Gawra XIII some new but sparsely applied techniques of decoration also appear, such as ribbing, incision and appliqué (Tobler 1950: 141).

Generally speaking, similarities between Hammam IV C and the contemporary sites in northeastern Syria and northern Iraq are not copiously attested, thus emphasizing the local traits in Hammam IV pottery development. It is suggested that in the course of time the influences from the east on Hammam IV pottery became weaker and weaker (a tendency already noted in Hammam IV B).

\subsubsection{Hammam IV D}

Hammam IV D is the least well-defined ceramic phase of the period IV ceramic sequence at Tell Hammam et-Turkman. The Hammam IV D pottery is closely related to Hammam IV C ceramics and is correlated to Gawra XIIA-XII and the later part of Leilan VI B. 
Hammam IV D is marked by a decrease in rim type variability. Very few new rim types were introduced and many of the Hammam IV C shapes are no longer found.

Bowls still constitute the most common type of pottery. Bead-rim bowls are preponderant in these late period IV levels. In the last Hammam IV D stratum, however, a sharp decline in bead-rim bowls is noticeable, accompanied by an increase of large plain-rim bowls. In the succeeding Hammam V A phase coarsely finished plain-rim bowls are extremely abundant and mostly replace the bead-rim vessels. At Tepe Gawra few vessels with outrolled rims were found in strata XIIAXII (cf.Tobler 1950, Pl. LXXIX-f). Bead rims constitute a common rim shape throughout the Hammam IV sequence but apparently are a late ceramic trait in northern Iraq.

At Tepe Gawra, undecorated and roughly shaped flat-based bowls are found in low numbers in stratum XII but become common in the next stratum XIA. Gawra XIIA-XII represent the last strata in which painted ware predominates (Tobler 1950: 146, 151). At Tell Hammam et-Turkman undecorated coarse ware constitutes the vast majority of the Hammam V A ceramic assemblage, but the origins of this kind of pottery are found in the preceding Hammam IV period.

Many new shapes are introduced in the Gawra strata XIIA-XII (ibid.: 146). Particularly large storage vessels become common. At Tell Hammam et-Turkman large jars and pots also increase in frequency at this time. Ring bases, which were first introduced in Gawra XIII, become extremely abundant in Gawra XIIA-XII (ibid.). At Tell Hammam et-Turkman ring bases are found in very low numbers throughout the Hammam IV period.

Generally, very few comparisons are found between Gawra XIIA-XII, Leilan VI $\mathrm{B}$ and Hammam IV D. Both in vessel shape and decoration the ceramic assemblages from these sites are completely different, thus indicating separately developing regional ceramic traditions. From a technological point of view, however, the differences between the various sites are much less evident, which suggests that technological innovations move along different channels than typological alterations in shape and design.

\subsection{Hammam $V$}

The period V pottery of Tell Hammam et-Turkman is closely related to the preceding Ubaid-related Hammam IV period and displays numerous affinities with the Late Chalcolithic ceramic traditions of northern Iraq, Syria and southeastern Turkey. Like the preceding Hammam IV pottery, the Hammam V ceramics were retrieved almost entirely from domestic deposits. Only the last Hammam V stratum represents what may be termed a "public area". This stratum is marked by monumental niched architecture, comparable with the Uruk temples of e.g. Tell Qannas, the Jebel Aruda or Uruk IV A. The complex was destroyed in a violent fire and thereupon at least this part of Tell Hammam et-Turkman was deserted for some time. Ceramics found in this monumental building clearly differ both in typological and technological aspects from those of the succeeding period VI (early third millennium). A hiatus is indicated, the duration of which is not exactly known (probably between 100 and 200 years).

Hammam V represents a homogeneous body of pottery, which can nevertheless be divided into two phases ( $\mathrm{A}$ and $\mathrm{B}$; $\mathrm{A}$ being the earliest). Hammam $\mathrm{V}$ ceramics 
resemble the Chaff-Faced Simple Ware of the Amuq F period (Braidwood and Braidwood 1960: $232 \mathrm{ff}$.), but it will be shown here that Amuq F ware is contemporary with the Hammam V B phase only. Its general features, however, do also hold for the earlier Hammam V pottery. A date around 3600-3200 B.c. (uncalibrated) is suggested here for the Hammam V period at Tell Hammam etTurkman.

\subsubsection{Hammam $V A$}

Hammam V A is marked by a large variety of pottery types. The most characteristic shape is represented by the so-called Coba bowls, which comprise almost half of the Hammam V A ceramic sample (Fig. 8: 118-121). In strata 2 and 3 particularly these coarse, handmade or perhaps mould-made vessels are extremely common. Most of the Coba bowls ${ }^{7}$ are plant or plant-and-lime tempered and they virtually always display a dark core. Usually they have a brown-orange colour and most examples are scraped, particularly near the base. These Coba bowls have a wide distribution (cf. Brown 1967: 132).

In Anatolia Coba bowl-like vessels were found at Norsün Tepe; here these bowls were described as "spätchalkolithische Besenstrichware" (Hauptmann 1972: 115). At the adjacent site of Korucutepe "wiped" or "flint-scraped" pottery is reported in the second half of the Late Chalcolithic phase B (Brandt 1978: 59), but no true Coba bowls seem to be present. When compared with Tell Hammam et-Turkman, the Late Chalcolithic phase B at Korucutepe seems to be more closely related to the post-Coba phase Hammam V B. In southeastern Anatolia, numerous fragments of Coba bowls have been found during excavations at Hayaz Höyük. Two C14 dates from level 5 at Hayaz suggest a date around 3600 B.c. for the Coba bowls and related ware (Thissen 1985: 84). Earlier excavations in southeastern Turkey have revealed the presence of Coba bowls at Mersin and at Sakçe Gözü. At Mersin, coarse "flint-scraped" pottery is noted in levels XIII-XII B (Garstang 1953: 174), but a corrugated vessel found in level XII (ibid., Fig. 120, 123: 4) points to a Hammam V $\mathrm{B}$ date for these levels. At Mersin, levels XIV-XIII have been heavily disturbed by pits, which may have caused mixing of material from various levels.

At Sakçe Gözü, Coba bowls are preponderant in strata IV A-IV C (du Plat Taylor et al.1950: 94 ff.). Parallels between Hammam V A and Sakçe Gözü IV AIV C exist in several aspects. At Sakçe Gözü some of Ubaid-related painted ware is still found, particularly in strata IV A-IV B. Painted ware is present in minute quantities in Hammam V A, creating an obvious link with the preceding Hammam IV period. Bead-rim vessels, which constitute a common shape at Tell Hammam etTurkman during both period IV and V, are introduced at Sakçe Gözü in stratum IV $\mathrm{B}$, but they become common in IV C. Some of these vessels display carination, which is a characteristic Hammam V B trait (Fig. 9: 150). A bowl with a rim curving in at a sharply cut angle is said to represent a very distinctive IV C type of pottery at Sakçe Gözü (du Plat Taylor et al. 1950: 100). At Tell Hammam et-Turkman this kind of pottery appears in phase V B (Fig. 8: 129, 130). In Sakçe Gözü IV C "red burnished ware" is also new (du Plat Taylor et al.: 100). Although different in shape, this kind

\footnotetext{
${ }^{7}$ The name is derived from the site of Coba Höyük/ quantities (cf. du Plat Taylor $e t$ al. 1950). Sakçe Gözü, where these bowls were found in large
} 
of pottery may resemble Hammam V A orange or red-slipped burnished ware. An incised sherd found in Hammam V A compares with the so-called "excised" ware of Sakçe Gözü IV C, which is related at this site to the last stage of the Coba bowl period (ibid.: 100). Incised ware is very rare at Tell Hammam et-Turkman.

In northern Mesopotamia, pottery similar to that of Hammam V A is found at Grai Resh and Tepe Gawra. Similarities in shape, however, between the assemblages from these sites and those of Tell Hammam et-Turkman are not copiously attested. At Tepe Gawra, stratum XI-A is the first stratum with a predominant amount of undecorated ceramics. Generally, stratum XI-A pottery is crudely and irregularly shaped, displaying a rough surface and a brown-buff colour. Vessel walls are thick and straw or coarse sand inclusions become common (Tobler 1950: 152). Two main types of bowl are present at Tepe Gawra : a) flat-based bowls with a sharply expanding vessel wall and a rough, irregular surface and b) hemispherical bowls, which often feature some kind of carination (ibid.). The flat-based bowls most closely resemble Hammam V A Coba bowls, whereas several types of hemispherical bowls compare with vessels in both Hammam V A and V B. Hemispherical bowls with a rather sharp carination and a contracting rim appear at Tell Hammam etTurkman as early as phase $\mathrm{V} \mathrm{A}$, but they become a characteristic ceramic trait in Hammam V B (Fig. 8: 130, 131, 133). Gawra XI-A also yielded an isolated beadrim bowl (Tobler 1950: 152 and PI. CXLI: 335), which is a very uncommon shape at Tepe Gawra. In Gawra XI-A several new pot shapes are introduced (ibid.: 153). The characteristic double-rimmed pots are also found at Grai Resh (Lloyd 1940: 19), but they are absent at Tell Hammam et-Turkman. Other types of pots at Gawra XI-A closely resemble the plain-rim hole-mouth and bead-rim hole-mouth pots of Hammam V A.

At Grai Resh, located in the plain of Sinjar, Coba bowls are said to be present in levels VI-IX (Lloyd 1940: 19). In these strata large quantities of late Northern Ubaid painted ware are found, which, according to Lloyd (1940: 19), are similar to Gawra XIII-VIII examples. Double-mouthed pots are also present (ibid.), and suggest a connection with Gawra XIA-IX (Tobler 1950: 153). So-called "Uruk grey ware" is noted in the subsequent levels IV-II at Grai Resh. A characteristic pot shape in these levels closely resembles the bead-rim pots with hole mouths of Hammam V B (Fig. 10: 151-153).

Telul eth-Thalathat has yielded double-mouthed pots and spouted vessels in levels III-II (Egami 1959: 7), thus suggesting parallels with Gawra XIA-IX and Grai Resh II-IV. Egami (1959: 6) seems to be inclined to take levels V-I at Telul eth-Thalathat together when ascribing Uruk-like features to the ceramics found in these levels. Probably they largely correspond to phase V B at Tell Hammam et-Turkman. The lower Late Chalcolithic phase V A at Tell Hammam et-Turkman seems to correlate with Telul eth-Thalathat levels VIIa and VI. Levels VIIb and VIIa at Telul eth-Thalathat are probably closely related with only a slight temporal difference between both levels (Egami 1959: 6), but whereas level VIIb is characterized by Ubaid-like painted ware, level VIIa merely shows unpainted reddishbrown or greenish-brown ceramics. Level VIIb at Telul eth-Thalathat may be correlated with the end of phase IV D at Tell Hammam et-Turkman, although there are also some parallels with Hammam IV C. Thus a large unpainted bowl 
with inward-bevelled rim from level VIIb at Telul eth-Thalathat (cf. Egami 1959, Fig. 53: 9) resembles a painted Hammam IV C vessel (Fig. 5: 55). It is interesting to note is that certain ribbed and incised jars from Telul eth-Thalathat levels IX and VIIb (Egami 1959, Fig. 53: 3, 54: 10) closely resemble some rare vessels from Gawra XIII (Tobler 1950, Pl. CXXXI: 217, 218). Here Gawra XIII is equated with Hammam IV C. At Tell Hammam et-Turkman we have noted a strong connection between Hammam IV C and Hammam IV D. Apparently this coherence in the later Northern Ubaid levels also existed in the east. The occurrence of ribbed and incised pottery found in Telul eth-Thalathat VIIb may be the result of ceramic developments which started as early as Gawra XIII in this area. At Tepe Gawra, ribbing as a decorative technique remains in use (although in a different manner) in strata XIIA-XII (Tobler 1950: 150), whereas incision is still found in strata XI-X (ibid.: 156). The next level VIIa at Telul eth-Thalathat shows affinities, both in fabric and vessel shape, with pottery found in the early strata of period V at Tell Hammam etTurkman. A large bowl with a protruding hammer-rim (Egami 1959, Fig. 52: 5) resembles a type of pottery found at Tell Hammam et-Turkman only in phase V A (Fig. 8: 116, 117, 122-124).

\subsubsection{Hammam $V B$}

Hammam V B comprises the pottery found in the last Late Chalcolithic strata at Tell Hammam et-Turkman. The ceramics show close affinities with those of the preceding Hammam V A phase, but many characteristic early period V types are no longer found and several new shapes are introduced. In techniques of pottery production, too, important changes take place (see section 3.4.). Hammam V B ceramics are found at many sites in southeastern Turkey, northern Syria and northern Iraq, e.g. Kurban Höyük, Tell Brak and Tepe Gawra.

Plain-rim bowls occur in rather small numbers in Hammam V B strata. Coba bowls are not found anymore. The most common bowl type is now represented by bead-rim vessels, which often have a carination just underneath the outrolled lip (Fig. 9: 150). These bead-rim vessels apparently took over the role of the Coba bowls in daily household activities. Hammam V B is marked by grey or black, often burnished, hole-mouth pots with bead rims (Fig. 10: 151-153) and by large, wide bowls, showing a great variety in rim shape. Large corrugated bowls (Fig. 9: 137139) compare with vessels found in the Late Chalcolithic phase B at Korucutepe, dated around 3400-3200 в.c. (Brandt 1978: 60). This dating closely agrees with radiocarbon dates from the last Hammam V B stratum at Tell Hammam etTurkman. Corrugated bowls were also found at Mersin XIII (Garstang 1953, Fig. 120, 123: 4) and Sakçe Gözü V A-VI (du Plat Taylor et al. 1950, Fig. 19: 8, 21: 3). The appearance of these vessels in periods V A-VI at Sakçe Gözü confirms the temporal assignment of this kind of pottery to the end of the 4th millennium B.c., since period V A immediately succeeds the Coba bowl phase IV at Sakçe Gözü (a development similar to Tell Hammam et-Turkman). Sakçe Gözü V A is clearly linked to the earlier period IV, but also indicates Uruk influences (du Plat Taylor $e t$ al. 1950: 102). A few bevelled rim bowls were found, unfortunately out of context.

In the next phase, V B, at Sakçe Gözü several new shapes were introduced, but, more important, a new fine greenish-cream ware appeared as well, used only for very 
thin, wheel-made cups. This new ware is probably comparable to the "Plain Simple Ware" of the Amuq plain (Braidwood and Braidwood 1960: $229 \mathrm{ff}$.). At Tell Hammam et-Turkman Plain Simple Ware is rare in period V. Period VI at Sakçe Gözü seems to be closely connected with the preceding period V. Large corrugated bowls are still present. Large hole-mouth pots which can be compared to Grai Resh II-IV are new (du Plat Taylor et al. 1950: 107). Similar vessels appear at Tell Hammam et-Turkman in phase V B. New also are bowls with a flattened bead-rim (ibid.,Fig. 21: 4), which constitute a common ceramic trait in Hammam V B (Fig. 9: 143, 145).

Kurban Höyük, situated in the Karababa region in southeastern Turkey, has yielded an important corpus of Late Chalcolithic material (Algaze et al. in press) divided into two periods : VI B and VI A (VI B being the earliest). Period VI B is only represented by a single phase of occupation. The pottery found in this phase consists almost entirely of Amuq F-related chaff-faced ware (ibid.: 17). The next period VI A consists of two phases of occupation. These levels give evidence of a gradual shift from chaff-faced pottery to grit-tempered wares. Grit-tempered pottery becomes the principal component in the terminal Late Chalcolithic levels at Kurban Höyük. At the same time an increasing occurrence of true Uruk pottery (i.e. bevelled rim bowls, four-lugged jars, drooping spouts) is observed. At Tell Hammam et-Turkman no Uruk pottery has been found. Although grit-tempered ceramics are commonly used in Hammam V B, plant-tempered pottery remains by far the largest component. Only Kurban VI B pottery compares with Hammam V B, whereas Kurban VI A ceramics probably fill the gap between Hammam V B and VI. At Hassek Höyük, also located in the Karababa area, characteristic Uruk pottery (bevelled-rim bowls, four-lugged jars) was found in level I, together with flower pots and reserved slip ware. The subsequent levels at Hassek Höyük all show distinctive early 3 rd millennium pottery. Hassek Höyük is closely comparable to Kurban Höyük VI A and indicates an uninterrupted development from the Late Chalcolithic into the Early Bronze Age I period (Behm-Blancke 1981).

In northeastern Syria Hammam V-related pottery has been excavated at Tell Brak and Tell Leilan. At the latter site, periods V-IV must correspond in chronological terms, at least partially, to Hammam V. At Leilan, periods V and IV are closely interrelated and yield locally developed ceramic assemblages marked by mainly straw-tempered, wide bowls with hammer-headed rims (Schwartz 1982, Fig. 41: 3, 5, 8 and 45: 3-5) and jars with triangular-shaped rims (ibid., Fig. $42: 3$ and 44: 3-4). Pottery comparable with Leilan V-IV ceramics appears at several sites in northern Mesopotamia and Syria in late 4th and early 3rd millennium contexts (see Schwartz 1982 for full references). The period IV assemblage at Tell Leilan is distinguished from period $\mathrm{V}$ by the introduction of bevelled-rim bowls. Until now, Uruk influence at Tell Leilan is solely demonstrated by bevelled-rim bowls; no other characteristic Uruk ceramic traits are found. The Leilan V-IV pottery shows close affinities with that of Kurban Höyük VI. Hammer-headed bowls are found in large quantities at both sites. An important difference, however, is indicated by the highly distinct nature of Uruk influence in the ceramic assemblages of Leilan and Kurban. Probably Kurban VI B overlaps with the later part of Leilan V, whereas Kurban VI $\mathrm{A}$ is related to Leilan IV. In this view, phase $\mathrm{V}$ at Tell Hammam et-Turkman 
corresponds temporally to Leilan V (not Leilan IV). The resemblances between both sites are, however, sparse. The characteristic bowls with hammer-headed rims of Leilan are rare at Tell Hammam et-Turkman; a few examples were found in Hammam V A (Fig. 8: 117, 122-124). A characteristic Hammam V B bowl shape (Fig. 9: 140-142) resembles some Leilan V vessels (Schwartz 1982, Fig. 45: 6-8). Leilan V yielded a few coarsely made bowls (ibid., Fig. 45: 15), which seem to compare with Hammam V A Coba bowls.

The chronological positioning of both Leilan IV and Kurban VI A in the late 4th millennium B.c. is confirmed by comparing the Uruk-influenced pottery from both sites with ceramics found in the late Uruk/Jemdet Nasr levels of Tell Brak (Fielden 1981; Oates 1985). Excavations in Area CH at Brak have yielded "Late Uruk/ Jemdet Nasr" pottery from levels 12-9. This pottery is marked by platters, casseroles, jars with finely corrugated rim interiors, large flat-based bowls and bevelled-rim bowls. Oates (1985: 176) suggests comparisons with Warka III rather than Warka IV for these ceramics. Before an apparent time gap, "Early Uruk" material, related to Grai Resh and Gawra XI, was found in Brak Area CH in levels 14 and 13. It should be noted that the hiatus between levels 13 and 12 is probably a local feature. Finds in areas other than $\mathrm{CH}$ suggest that on other parts of the mound, occupation levels may be attested which fill this gap in Area CH (ibid.: 178). Recent excavations at Tell Brak (1986) have yielded material closely related to Hammam V A in Area CH levels 22-15 (Joan Oates, personal communication). Coba bowls found in these levels are definitely earlier than bevelled-rim bowls. The Brak sequence largely confirms the chronological framework based on the soundings at Tell Hammam et-Turkman. At the latter site true Uruk pottery is absent. A hiatus is indicated between the burnt monumental building of the last Hammam V B stratum and the beginning of the next period VI, marked by early 3rd millennium (EB I) pottery. This gap in occupation at Tell Hammam et-Turkman (or at least at the temple site excavated on the mound) seems to coincide with the introduction of true Uruk wares at Brak CH 12-9, Leilan IV, Kurban VI A and Hassek Höyük I. The one-period Uruk sites of Jebel Aruda and Habuba Kabira-South seem to fit within this time span (which is also indicated by a radiocarbon date from the latter site, cf. Strommenger 1973: 170). The "Uruk" or, more properly, Late Uruk/Jemdet Nasr period in Syria may be dated between $3200-3000$ B.c. (uncalibrated).

The paucity of similarities between the Khabur drainage and the Balikh region is emphasized here; apparently the ties between both areas were weakly developed. This is even more true for the remote sites in northern Iraq. The main comparisons between the northern Iraqi sites and Tell Hammam et-Turkman are found in fabric rather than in vessel shape. The Northern Ubaid-related Hammam IV period already gave evidence of a strong trend towards regional variability in pottery manufacture. This trend continued into the Hammam V period and may be part of a more general rise of locally-oriented socio-political units.

At Tepe Gawra, strata XI-IX are marked by a predominance of coarse and undecorated ceramics. This pottery shows little variety in rim and vessel shape (Tobler 1950: 154). Most common are hemispherical bowls, some of which have bead rims. In the lower strata at Tepe Gawra bead rims constitute an extremely rare ceramic trait. A few hole-mouth pots were found at Gawra (ibid., Pl. CXLVI: 402 
404), which show resemblances to a group of Hammam V A-V B hole-mouth vessels with outrolled lips (Fig. 10: 151-153). Coarsely made flat-based bowls are also numerous at Gawra (ibid.: 155). These vessels closely resemble a bowl shape found in stratum XI-A and seem to have remained in use until stratum VIII (cf. Speiser 1935: 41). Painted pottery is found in low numbers in Gawra XI-IX and is marked by a new style of decoration (Tobler 1950: 155). Most common are repetitious patterns of cross-hatched triangles or simply horizontal bands. At Tell Hammam et-Turkman this style of painting is also found, but it is here limited to phase B only. This Late Chalcolithic painted pottery resembles the painted and incised wares of Habuba Kabira-South (Sürenhagen 1978). Few burnished vessels are found in strata XI-XA at Tepe Gawra. Burnishing is restricted to small gray or black angle-necked jars (Tobler 1950: 155). Burnishing constitutes a characteristic Hammam V B ceramic feature. In these late Hammam V strata burnishing is applied only to large grey or black bowls and hole-mouth pots.

At Grai Resh so-called "Uruk grey ware" appeared in levels IV-II (Lloyd 1940: 118). In connection with this grey ware bevelled-rim bowls and spouted vessels were found. Both kinds of pottery are absent at Tell Hammam et-Turkman. A close parallel between Tell Hammam et-Turkman and Grai Resh is constituted by a type of hole-mouth pot with bead rim (Fig. 10: 151-153). The absence of Uruk-related pottery at Tell Hammam et-Turkman suggests that Hammam V B correlates only with the earlier part of the Grai Resh IV-II sequence.

In western Syria excavations at Tell Judaidah, Chatal Höyük and Tell Dhahab, all located in the Amuq plain, have yielded a mass of Late Chalcolithic pottery. These ceramics, termed phase $\mathrm{F}$ in the Amuq sequence, are marked by the largescale appearance of "Chaff-Faced Simple Ware". Until now, most Late Chalcolithic pottery in northern Syria and surrounding regions has been defined in terms of similarity to Amuq F ware. Generally, few comparisons are found between Hammam V ceramics and Amuq F pottery. Coba bowls seem to be absent in the Amuq $\mathrm{F}$ assemblage, which suggests a late date, towards the end of the 4 th millennium B.c., for phase F ceramics. Bowls with turned-in and outrolled rims were now common (Braidwood and Braidwood 1960: 233). Jars with bead rims are found in large quantities (ibid.: 236 and note 12). Few such vessels were already present in phase E, which is separated by a considerable time gap from phase $\mathrm{F}$ in the Amuq. At Tell Hammam et-Turkman outrolled lips are commonly distributed throughout periods IV and V, but are most numerous in the late phase V B (cf. Fig. 9: 144-146, 148-150). A group of Amuq F inner-ledge bowls (Braidwood and Braidwood 1960, Fig. 174: 13, 14) resembles a characteristic Hammam V B type of bowl (Fig. 9: 140 142). Carinated bowls are common in the Amuq F repertoire (Braidwood and Braidwood 1960, Fig. 174: 5-8, 18-23) and constitute another comparison with Hammam V B. Parallels between the Amuq F and Hammam V ceramics are also found in low-collared jars with interior channeled rims (Fig. 10: 156, 157 ; cf. Braidwood and Braidwood 1960: 235 and Fig. 176: 10-15). At Tell Hammam etTurkman, these vessels appear only in phase V B. At Tell Brak, jars with corrugated rim interiors constitute a distinctive "Late Uruk/Jemdet Nasr" trait (Oates 1985: 176). Amuq F pottery is best compared with Hammam V B ceramics. None of the characteristic Hammam V A shapes seems to be present in the phase F pottery of the 
Amuq. When comparing the excavations at Tell Hammam et-Turkman with the soundings in the Amuq, it is not surprising to find that Amuq F ceramics can be related only to the later part of the 4th millennium B.c. At Tell Hammam etTurkman "chaff-faced" pottery turned up already in the later stages of the Ubaidrelated Hammam IV period and reached its peak in the subsequent Hammam V period, thus giving evidence of a long development of Late Chalcolithic pottery production. In the Amuq, on the other hand, phase F remains were traced to such a limited extent, that one can hardly expect this phase to represent a complete sequence of Late Chalcolithic pottery. At Tell Judaidah only two architectural levels, slightly more than one metre in depth, are assigned to phase F (Jk3: 22, Jk3: 21; Braidwood and Braidwood 1960: 226).

Late Chalcolithic pottery has been found at Tabara al-Akrad, another site in the Amuq plain (Hood 1951). Levels VII-V at Tabara have yielded pottery which seems to be best compared to Amuq F ware. Comparisons with Hammam V pottery are only sparsely attested. A group of small, restricted, and often coarsely painted bowls, found in level VII at Tabara, suggests similarities with some Hammam V A restricted vessels (Fig. 6: 81, 82, 84) whereas some vessels found in levels VI-V (e.g. grey-burnished bead-rim bowls) indicate resemblances with the grey or blackburnished ware of Hammam V B. Low-collared jars and hole-mouth pots resemble Uruk shapes (Hood 1951: 128) and also point to a late Hammam V date.

Hammam V B-related pottery has also appeared in Hama levels K9-7. Shallow carinated bowls with bead rims (Fugmann 1958, Fig. 30b: 5B842 and 37: 7A634, 4B618) and large low-collared jars with simple rounded or bevelled rims (ibid., Fig. 37b: 7A641, 7A632, 7A630) compare with some characteristic Hammam V B shapes (Fig. 10). In Hama K8 a few bevelled rim bowls were found (Fugmann 1958, Fig. 37: 5B840), suggesting a date around the end of the 4th millennium B.C.

\section{Relative chronology : the technological development \\ 3.1. Introduction}

The typological framework outlined in the previous section is confirmed by the technological development of Hammam IV-V pottery. It should be stressed that, although on typological grounds four phases are distinguished in period IV and two phases in period V, several of these phases are closely interrelated, viz., Hammam IV A-IV B, Hammam IV C-IV D and Hammam V A-V B. This interrelationship is emphasized by the technological development, which also indicates three main steps in Hammam IV-V pottery manufacture.

Unfortunately, little information on technological aspects of pottery production is at present available from other sites. Until now, emphasis in ceramic studies has been almost entirely on typological aspects, thereby largely neglecting the ultimate basis on which typological developments are founded. A particular vessel or rim shape, or a style of decoration, is dependent on the way in which a potter deals with his material, i.e. type of clay, tempering material, firing techniques and surface treatment (Franken 1974).

The comparative chronological framework outlined in the previous pages was based on an internal sequence of Hammam IV-V vessel, rim and decoration "types" and on a comparison of this sequence with those of neighbouring sites. However, one 
is struck by the fact that comparisons based on rim or decoration typology between the various sites are in many instances limited to a few examples only, whereas the ceramic assemblage as a whole is hardly comparable. Apparently a strong regional variability in rim shape or decoration outline existed during these prehistoric times. The fact that two sites, each with their own ceramic repertoire, share one or two rim shapes, may have little meaning, particularly if it is unknown which functional, spatial or temporal variables underlie this resemblance. An insight into techniques of pottery production at various sites may lead to an understanding of change and continuity in ceramic development, and may give the typological analysis a firmer basis.

All Hammam IV-V vessels seem to have been locally made. No convincing evidence was found that pottery was brought to Tell Hammam et-Turkman from other sites in or outside the Balikh region. Local pottery manufacture is indicated by the presence of some wasters. The vast majority of Hammam IV-V pottery is handmade. Only a minute fraction of the late Hammam V assemblage points to the use of a fast turning device. Some kind of slow turntable or tournette, however, may already have been widely employed in earlier times. Many sherds display more or less parallel finger striations, suggesting the use of a turning board or mat. Particularly, larger vessels, which cannot be shaped in the hand, require the use of some kind of turntable.

\subsection{Hammam IV $A-I V B$}

The pottery found in the early Hammam IV phases is almost entirely mineraltempered, fine sand and lime being the common means of temper. In phases IV AIV B at Tell Hammam et-Turkman over $90 \%$ of the pottery showed exclusively mineral inclusions, whereas a minute fraction $(2.2 \%)$ indicated solely vegetable temper. Fine sand temper was most extensively employed in phase IV A (here $c a$. $52.6 \%$ of the pottery was sand-tempered), but shows a sharp decrease in use in Hammam IV B $(c a .21 .7 \%)$. Lime now took over the role of fine sand. In Hammam IV B almost $70 \%$ of the pottery indicates lime temper. An obvious trend towards a diminishing use of fine sand as a means of temper is visible throughout the Hammam IV sequence until fine sand virtually disappears in the late Hammam IV D strata. In the subsequent Hammam V period fine sand temper was only sporadically used. Generally, Hammam IV A-IV B vessels were well-fired. Ceramics with dark cores, indicating incomplete oxidation, appear in low quantities in phases IV A-IV B (IV A: $10 \%$; IV B: $12.1 \%$ ). Most of the Hammam IV A-IV B ware has a smoothed appearance ; scraping is mostly limited to the vessels' lower part. The vast majority of the pottery is cream-buff coloured. A characteristic trait of the lower phases IV A-IV B is the large amount of painted ware, although already in these early levels a clear trend towards diminishing use of painting is perceptible.

\subsection{Hammam IV C-IV D}

These phases produce evidence of important changes in pottery manufacture at Tell Hammam et-Turkman. At the beginning of Hammam IV $\mathrm{C}$ a rapid change takes place in tempering materials. Whereas in the lower phases IV A-IV B vessels were 
mainly mineral-tempered, the emphasis is now on vegetable inclusions. In Hammam IV A-IV B $1.3 \%$ and $3.3 \%$ respectively of the pottery showed vegetable tempering materials. In Hammam IV C $52.6 \%$ of the pottery indicated vegetable temper, and in the subsequent phase IV D this amount had increased to $83.5 \%$ of the ceramic sample! This trend toward increasing use of vegetable temper materials continues into the next Hammam V period. Interestingly enough, a great diversity in temper material is perceptible simultaneously with the sharply increasing use of vegetable temper in Hammam IV C. A development towards variability in temper materials is already visible in the lower Hammam IV A-IV B strata, but it reaches its peak in Hammam IV C. This may indicate experiments in tempering techniques and thus in pottery production as a whole. Alterations in pottery manufacture are also suggested by important changes in other stages of the process of vessel construction. In Hammam IV C-IV D the amount of pottery showing a dark core increases considerably. In Hammam IV C about $27.5 \%$ of the pottery has a dark core, whereas in Hammam IV D $44.6 \%$ of the ceramics shows such a dark core. This dark core, indicating incomplete oxidation, may be the result of firing at low temperatures, but more likely it is the product of firing at a high temperature during a short time only (the firing time is then not sufficient to allow complete oxidation). By firing during a short time, a sufficiently hard vessel surface was produced and at the same time large quantities of fuel were saved. Closely correlated with this apparent decrease in firing time is the increasing use of vegetable temper. Since plant inclusions act as fuel within the vessel, only a short firing time is required. Limetempered vessels also need only a relatively short firing time, but when compared to plant-tempered ceramics they have the disadvantage of lime decomposition (and thus destruction of the vessel) when exposed to high temperatures. The use of plant temper has several advantages in comparison with mineral inclusions: besides the short firing time and the resulting reduction in fuel required, plant-tempered vessels demand only little special attention during firing and have a strong resistance to thermal shock due to large pore size. The Hammam IV sequence seems to indicate that reduction of firing time served not only to save fuel but also to increase the possible rate of production; a trend towards cheaper production on a larger scale is suggested.

The use of vegetable inclusions gives vessels a coarser outer appearance and requires thicker vessel walls. Hammam IV C-IV D shows a steady increase in coarsely scraped pottery, quite different from the often smoothed vessels found in the early strata. The application of decorative techniques becomes difficult; the rather coarse vessels do not allow subtle painting or incision. In Hammam IV C-IV D a sharp decrease in painting is perceptible. Whereas in Hammam IV B $13.4 \%$ of the pottery was still painted, this percentage is reduced to $6.2 \%$ in Hammam IV C and $2.4 \%$ in Hammam IV D. From an aesthetic point of view the late Hammam IV pottery in general becomes less attractive, but apparently the economical advantages fully compensated for the aesthetic drawbacks. In this sense, the coarse late Hammam IV ceramics (and those of the even more economically oriented Hammam $\mathrm{V}$ period) do not represent a stage of cultural decline, but represent a perfect adaptation to changing socio-economic demands. 


\subsection{Hammam $V A-V B$}

The important innovations in pottery manufacture that started in the later stages of the Hammam IV period finally culminated in Hammam V A-V B. All ceramic evidence of period $\mathrm{V}$ at Tell Hammam et-Turkman points to a large-scale, almost industrial mode of pottery production. The vast majority of pottery found in these phases is vegetable tempered. In Hammam V A about $96.6 \%$ of the pottery shows plant inclusions and $98.4 \%$ gives evidence of a dark core. Most of the pottery is scraped $(96.9 \%)$ and has a coarse appearance. Decoration is rare $(1.1 \%)$ and virtually limited to small smoothed and lime-tempered bowls. The most common shape in these levels is represented by the coarse, irregularly shaped Coba bowls. In the later part of Hammam V ceramic development some important changes take place. Hammam V B shows a sharp decline in plant-tempered ceramics $(60.3 \%)$. Mineral-tempered ceramics now increasingly gain importance. At the same time a diversity in tempering material is visible. Calcite becomes a characteristic tempering material in Hammam V B, but is virtually limited to cooking pots (calcite temper gives a vessel a strong resistance against thermal shock). In the lower Hammam IV and V strata calcite is hardly used. Related to the changes in tempering material are alterations in firing techniques. Pottery fired in a reducing atmosphere appears. A group of wide bowls and hole-mouth pots is evidence of intentional blackening by carbon deposition in a reducing atmosphere. This technique is extremely rare in levels preceding phase V B.

\subsection{The technological development: conclusions}

At Tell Hammam et-Turkman, the ceramic sequence produces evidence for important changes in pottery manufacture through time. A shift from rather thinwalled and smoothed ceramics to coarsely finished fabrics is perceptible. Particularly, the painted ceramics are sensitive indicators of change in manufacture techniques. The early strata at Tell Hammam et-Turkman show elaborately and busily painted ceramics, but in later levels more and more emphasis is laid on simple designs, such as broad bands or undulating lines. This obvious change in style of painting is accompanied by a trend towards less frequent use of painting. It has been shown that technological alterations basically explain the changes in decoration and, ultimately, the decrease in painted ware through time. In turn, these technological changes may be considered as adaptations to changes in the socio-political constitution, which demanded large-scale and low-cost pottery production. At Tell Hammam et-Turkman, the Northern Ubaid-related painted ware is an intrusive or "borrowed" ceramic trait. Although locally produced, the technique and style of painting seem to be wholly derived from northern Mesopotamian examples. At sites in northeastern Syria and northern Iraq painted ware is much more common than in the Balikh area. But here too a trend towards simpler painting and less frequent use of decoration is perceptible. Gawra XVI-XV already yielded a large group of undecorated pottery (although painted ware remained in the majority). At the same time a reduction in number of vessel shapes and design motifs is to be noted (Tobler 1950: 138). Design execution also became less elaborate and broad bands were now common. In Gawra XIII ring bases were introduced, which became extremely numerous in the subsequent strata XII-A and XII. These ring bases may point to 
the use of some kind of turning device, which would imply important changes in vessel manufacture. In stratum XII at Gawra much wider use of the tournette or slow wheel is reported (Tobler 1950: 146). Rather coarsely made, thick vessels are now common. A remarkable increase in undecorated pottery is noted. Strata XIIAXII are the last levels at Tepe Gawra in which painted wares predominate. The subsequent strata XI-IX are marked by coarse and irregularly shaped pottery. Crude flat-based bowls appear in large quantities. In stratum IX a few vessels were found which had been produced by means of the fast wheel. In the succeeding stratum VIII most of the pottery was wheelmade. It will be noted that this short summary of technological developments in the ceramics of Tepe Gawra points to some trends which are paralleled by technological changes in the Hammam IV-V pottery. This similarity in technology is found whenever Tell Hammam et-Turkman is compared with other sites in Syria or surrounding areas. The Amuq F assemblage, for example, closely resembles Hammam $\mathrm{V}$ ceramics in fabric, although from a point of view of rim typology the connection is rather weakly established. While comparisons of type of rim or decoration between Tell Hammam et-Turkman and other sites give evidence of a strong variability, thus suggesting locally-bound and largely independent developments in pottery production, a technological comparison indicates strong similarities in pottery development between various sites in different regions. The changes in pottery technology are probably related to alterations in settlement organization. The general trend towards urbanization in the late 5 th and 4 th millennium is necessarily accompanied by shifts in pottery technology in order to respond to the changing requirements of society. A largescale, industrial mode of pottery production is developed. Throughout Syria and northern Mesopotamia the changing demands on the potters' craft are fundamentally met with in a similar way, but in stylistic execution of the ceramic products the urban centres remained largely autonomous.

\section{Absolute chronology : radiocarbon dates}

Several radiocarbon dates are available from Tell Hammam et-Turkman to support the period IV-V sequence.

All dates, however, stem either from the lower phases IV A and IV B or from the end of Hammam V B. All dates given here are uncalibrated. At present, only few C14 dates are available for the Northern Ubaid and Late Chalcolithic periods in Syria and northern Mesopotamia. Detailed lists of radiocarbon dates from more or less contemporary sites in various regions of the Near East are found in e.g. Schwartz (1982) and Oates (1982).

Two samples from Hammam IV A and IV B are to be rejected : sample GrN13039 yielded a date of $10,280 \pm 90$ BP which is clearly much too old, whereas sample GrN-1304l indicated a date of $5760 \pm 80 \mathrm{BP}$ which is too young to date phase IV A. More suitable seem to be the two remaining samples from phase IV B $(\mathrm{GrN}$ 13038 and GrN-13040), which gave a date of $6110 \pm 80$ and $6110 \pm 100$ BP respectively. These samples suggest a date around 4200-4100 B.C. for phase IV B. This would point to a date of $4400-4200$ B.c. for the preceding phase IV A, the earliest phase excavated at Tell Hammam et-Turkman. Unfortunately, virgin soil has not yet been reached at Tell Hammam et-Turkman, but on the basis of a drilling 


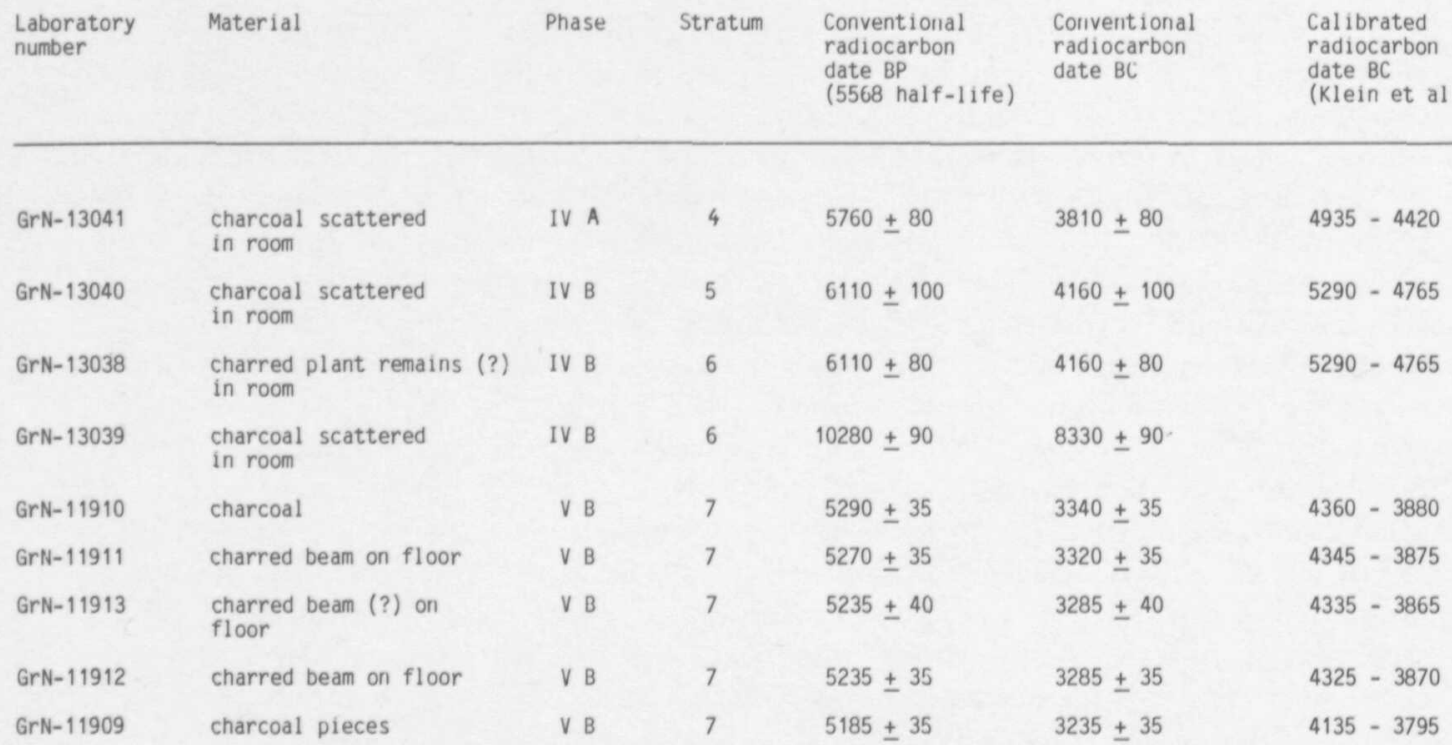

Radiocarbon dates from Tell Hammam et-Turkman.

we do not expect a debris accumulation of more than about one metre underneath the lowest Hammam IV A stratum reached. Northern Ubaid-related ceramics seem to have been introduced at Tell Hammam et-Turkman around $4500 / 4400$ B.c. It should, however, be noticed that earlier cultural phases are expected at our site. On the surface of the mound and in the various trenches a small number of true Halaf pottery fragments were found.$^{8}$ Apparently a Halaf settlement is present somewhere at Tell Hammam et-Turkman, but deeply buried underneath later remains. Here a date around $3700 / 3600$ B.c. is suggested for the end of the Hammam IV period. A C14 date of $3837 \pm 72$ в.c. from stratum XII at Tepe Gawra also points in this direction (Lawn 1973: 371-72). Gawra XII is related to the last strata of phase IV D at Tell Hammam et-Turkman. The beginning of the subsequent phase V A, marked by Coba bowls, may be placed around 3600 B.c., according to radiocarbon evidence from Hayaz Höyük, situated in the Turkish Karababa region (Thissen 1985: 84). These Coba bowls and related vessels are a clear outgrowth of late Hammam IV ceramic developments.

The end of the Hammam V period is tentatively placed around $3200 / 3100$ B.c. The monumental niched building of the last Hammam V B stratum was destroyed by fire. Excavations here yielded five C14 dates ranging between 3400 and 3200 B.c. All samples were taken from large beams (probably part of the roof construction).

\section{Concluding remarks}

The chronological periodization proposed here is outlined in the accompanying table. This chronology is based on a detailed and lengthy sequence of 5 th and 4 th

\footnotetext{
${ }^{8}$ The excavated Halaf sherds at Tell Hammam et-Turkman are out of context and are intrusive in

the various levels (perhaps as a result of mud brick production).
} 


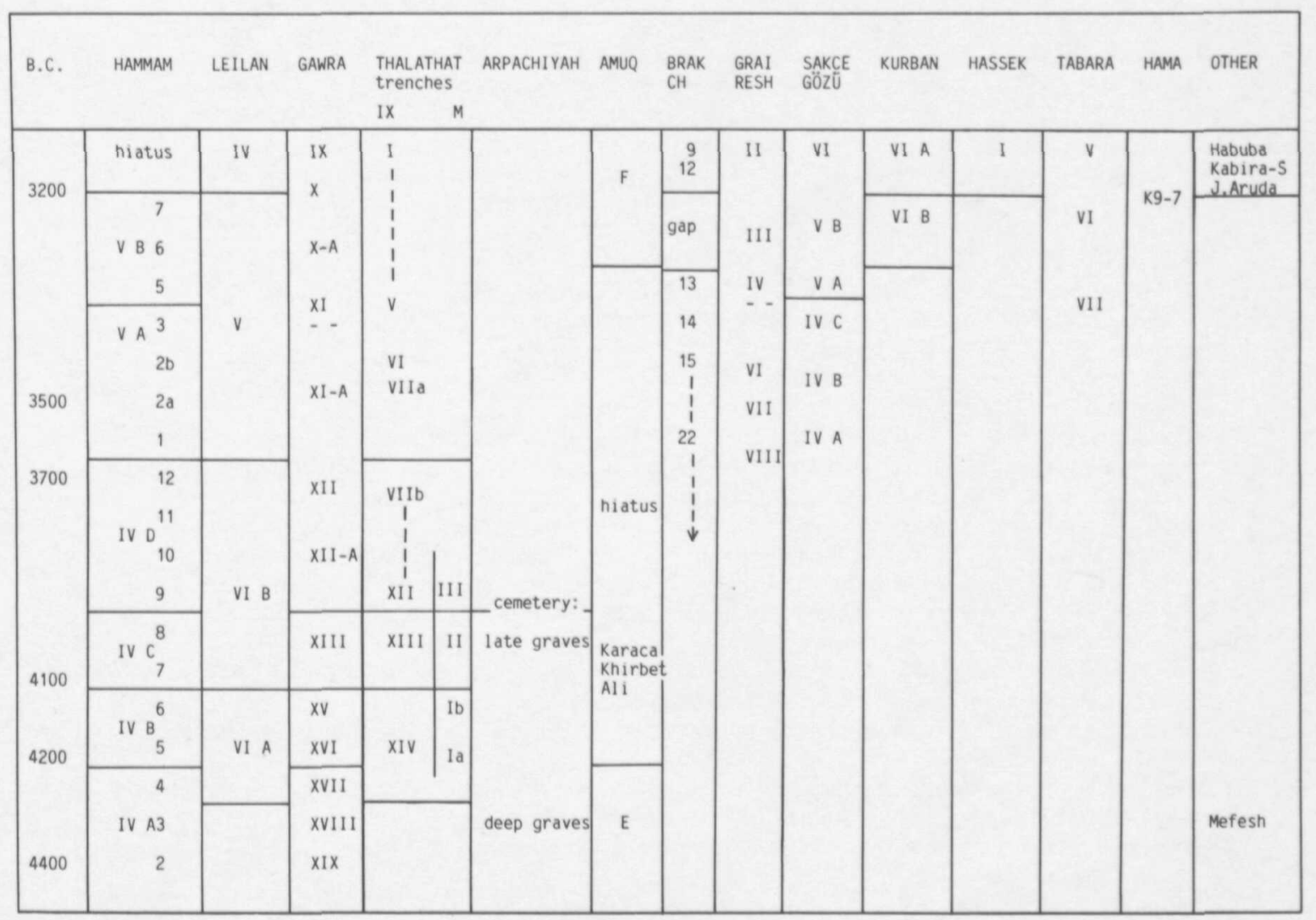

Chronological table.

millennium ceramics from Tell Hammam et-Turkman. By means of a quantitative typological and technological analysis of prehistoric Hammam IV-V pottery a sound framework has been established for comparison with contemporary sites in neighbouring regions.

So far as the Northern Ubaid and Late Chalcolithic periods are concerned, this chronological scheme replaces the chronology of Syria and northern Mesopotamia outlined in the 1965 edition of Chronologies in old world archaeology (cf. Watson 1965 ; Porada 1965), which has served for a long time as a basic framework of relative chronology. It also deviates in some respects from the recently revised relative chronology of Mesopotamia (cf. Dunham 1983).

\section{Bibliography}

Akkermans, P.M.M.G., in press, The period IV pottery, in: M.N. van Loon, Ed., Hammam etTurkman I, Leiden.

Akkermans, P.M.M.G., in press, The period V pottery, in: M.N. van Loon, Ed., Hammam et-Turkman I, Leiden.

Algaze, G. et al., in press, The Chicago Euphrates archaeological project 1980-1984 : an interim report.

Behm-Blancke, M.R. et al., 1981, Hassek Höyük: vorläufiger Bericht über die Ausgrabungen der Jahre 1978-1980, Istanbuler Mitteilungen 31: 5-93. 
Braidwood, R.J. and L.S. Braidwood, 1960, Excavations in the plain of Antioch I, O.I.P. LXI, Chicago. Brandt, R.W., 1978, The chalcolithic pottery, in: M.N. van Loon, Ed., Korucutepe vol. 2, Amsterdam. Brown, G.H., 1967, Prehistoric pottery from the Antitaurus, Anatolian Studies 17: 123-64.

Courtois, J.-C., 1962, Contribution à l'étude des niveaux II et III, in: C.F.A. Schaeffer, Ed., Ugaritica IV: $329-414$.

Driel, G. van, and C. van Driel-Murray, 1979, Jebel Aruda 1977-1978, Akkadica 12: 2-28.

Dunham, S., 1983, Notes on the relative chronology of early northern Mesopotamia, The Journal of the Ancient Near Eastern Society 15: 13-38.

Egami, N., 1959, Telul eth-Thalathat : the excavation of tell II, vol. I, Tokyo.

Fielden, K., 1981, A late Uruk pottery group from Tell Brak, 1978, Iraq 43: 157-66.

Franken, H.J., 1974, In search of the Jericho potters, Amsterdam.

Fugmann, E., 1958, Hama, Copenhagen.

Fukai, S. et al., 1970, Telul eth-Thalathat: the excavation of tell II (1964), vol. II, Tokyo.

Garstang, J., 1953, Prehistoric Mersin, Oxford.

Goldmann, H., 1956, Excavations at Gözlü Kule, Tarsus, vol. II, Princeton.

Hauptmann, H., 1972, Die Grabungen auf dem Norsün Tepe, 1970, Keban Project 1970 Activities, Ankara, 103-17.

Hood, S., 1951, Excavations at Tabara el-Akrad, 1948-49, Anatolian Studies 1: 113-47.

Klein, J. et al., 1982, Calibration of radiocarbon dates: tables based on the consensus data of the workshop on calibrating the radiocarbon time scale, Radiocarbon 24: 103-50.

Lawn, B., 1973, University of Pennsylvania radiocarbon dates XV, Radiocarbon 15: 367-81.

Lloyd, S., 1940, Iraq government soundings at Sinjar, Iraq 7: 13-21.

Loon, M.N. van, 1982, Hammam et-Turkman on the Balikh: background and first results of the University of Amsterdam's 1981 excavation, Akkadica 27: 30-45.

Loon, M.N. van, 1983, Hammam et-Turkman on the Balikh: first results of the University of Amsterdam's 1982 excavation, Akkadica 35: 1-11.

Loon, M.N. van, 1985, Hammam et-Turkman on the Balikh: first results of the University of Amsterdam's 1984 excavation, Akkadica 44: 21-40.

Loon, M.N. van, and D.Meijer, 1983, Hammam et-Turkman on the Balikh, Annales Archéologiques Arabes Syriennes 33: 299-313.

Mallowan, M.E.L., 1970, The development of cities from Al-Ubaid to the end of Uruk 5, in: I.E.S. Edwards et al., Eds., The Cambridge ancient history I: prologomena and prehistory, Cambridge, 327-462.

Mallowan, M.E.L. and J.C. Rose, 1935, Excavations at Tall Arpachiyah, 1933, Iraq 2: 1-178.

Oates, J., 1982, Ubaid Mesopotamia reconsidered, in: T.Cuyler Young, Jr., Philip E.L. Smith and Peder Mortensen, Eds., The hilly flanks and beyond, SAOC 36: 251-81. Chicago.

Oates, J., 1985, Tell Brak: Uruk pottery from the 1984 season, Iraq 47: 175-186.

du Plat Taylor, J. et al., 1950, The excavations at Sakçe Gözü, Iraq 12: 53-138.

Porada, E., 1965, The relative chronology of Mesopotamia. Part 2: seals and trade (6000-1600 B.c.), in: R.W. Ehrich, Ed., Chronologies in old world archaeology, Chicago and London, 133-200.

Schwartz, G.M., 1982, From prehistory to history on the Habur plains: the operation 1 ceramic periodization from Tell Leilan, Ph.D., Yale University.

Speiser, E.A., 1935, Excavations at Tepe Gawra I, Philadelphia.

Strommenger, E., 1973, Ausgrabungen in Habuba Kabira und Mumbaqat, Archiv für Orientforschung 24: $168-71$.

Sürenhagen, D., 1978, Keramikproduktion in Habuba Kabira-Süd, Berlin.

Thissen, L.C., 1985, The Late Chalcolithic and Early Bronze Age pottery from Hayaz Höyük, Anatolica 12: 75-130.

Thomas, D.H., 1976, Figuring anthropology, New York.

Tobler, A.J., 1950, Excavations at Tepe Gawra II, Philadelphia.

Watson, P.J., 1965, The chronology of north Syria and north Mesopotamia from 10,000 B.C. to 2000 B.C., in: R.W. Ehrich, Ed., Chronologies in old world archaeology, Chicago and London, 61-100. 


\section{Catalogue of Pottery}

\section{Fig. 2: Hammam IV A pottery}

1. Sand temper. Smoothed surface. Buff colour. Brown paint. D.21 cm.

2. Temper not visible. Smoothed surface. Cream colour. Black paint. D. $11 \mathrm{~cm}$.

3. Sand temper. Smoothed surface. Cream colour. Brown paint. D.16 cm.

4. Sand temper. Smoothed surface. Buff colour. Black paint. D.15 cm.

5. Temper not visible. Smoothed surface. Buff colour. Black paint. D. $12 \mathrm{~cm}$.

6. Lime temper. Smoothed surface. Buff colour. Brown paint. D. $14 \mathrm{~cm}$.

7. Sand temper. Smoothed surface. Buff colour. Brown paint. Coarsely executed design. D.15 cm.

8. Temper not visible. Smoothed surface. Cream colour. Brown paint. D.11 cm.

9. Lime temper. Smoothed surface. Greenish colour. Brown paint. D.11 cm.

10. Lime temper. Smoothed surface. Buff colour. Brown paint. D. $10 \mathrm{~cm}$.

11. Sand temper. Smoothed surface. Cream colour. Brown paint. D.15 cm.

12. Lime temper. Smoothed surface. Cream colour. Black paint. D. $10 \mathrm{~cm}$.

13. Lime temper. Smoothed surface. Buff colour. Brown paint. D.13 cm.

14. Temper not visible. Smoothed surface. Cream colour. Brown paint. D.15 cm.

15. Temper not visible. Smoothed surface. Buff colour. Brown paint. D. $15 \mathrm{~cm}$.

16. Lime temper. Smoothed surface. Cream colour. Brown paint. D.10 cm.

17. Lime temper. Smoothed surface. Cream colour. Brown paint. D.14 cm.

18. Lime temper. Smoothed surface. Buff colour. Brown paint. D.7 cm.

19. Lime temper. Smoothed surface. Reddish-brown colour. Dark core. Brown paint. D.15 cm.

20. Sand temper. Smoothed surface. Buff colour. Brown paint. D. $10 \mathrm{~cm}$.

21. Lime temper. Smoothed surface. Cream colour. Brown paint. D.13 cm.

22. Lime temper. Smoothed surface. Cream colour. Brown paint. D.13 cm.

\section{Fig. 3: Hammam IV A pottery}

23. Lime temper. Smoothed surface. Buff colour. Brown paint. D.17 cm.

24. Temper not visible. Smoothed surface. Cream colour. Black paint. D.15 cm.

25. Lime temper. Smoothed surface. Cream colour. Brown paint. D. $11 \mathrm{~cm}$.

26. Temper not visible. Smoothed surface. Buff colour. Brown paint. D. $10 \mathrm{~cm}$.

27. Lime temper. Smoothed surface. Cream colour. Brown paint. D. $14 \mathrm{~cm}$.

28. Temper not visible. Smoothed surface. Cream colour. Brown paint. D.14 cm.

29. Lime temper. Smoothed surface. Buff colour. Brown paint. D. $18 \mathrm{~cm}$.

30. Sand temper. Smoothed surface. Cream colour. Brown paint. D. $25 \mathrm{~cm}$.

31. Lime temper. Smoothed surface. Cream colour. Brown paint. D. $21 \mathrm{~cm}$.

32. Lime temper. Smoothed surface. Cream colour. Brown paint. D. $23 \mathrm{~cm}$.

33. Lime temper. Smoothed surface. Cream colour. Brown paint. D. $18 \mathrm{~cm}$.

34. Sand temper. Smoothed surface. Buff colour. Brown paint. D.11 cm.

35. Lime temper. Smoothed surface. Cream colour. Brown paint. D.19 cm.

36. Sand temper. Smoothed surface. Buff colour. Brown paint. D.16 cm.

37. Lime temper. Smoothed surface. Orange colour. Brown paint. D.15 cm.

38. Lime temper. Smoothed surface. Buff colour. Brown paint. D.17 cm.

39. Lime temper. Smoothed surface. Greenish colour. Black paint. D.11 cm.

\section{Fig. 4: Hammam IV B pottery}

40. Sand temper. Smoothed surface. Buff colour. Black paint. D.15 cm.

41. Lime temper. Smoothed surface. Buff colour. Reddish-brown paint. D. $10 \mathrm{~cm}$

42. Lime temper. Smoothed surface. Cream colour. Brown paint. D.11 cm.

43. Sand temper. Smoothed surface. Buff colour. Brown paint. D.11 cm.

44. Temper not visible. Smoothed surface. Buff colour. Brown paint. D.11 cm.

45. Lime temper. Smoothed surface. Buff colour. Brown paint. D.11 cm.

46. Lime temper. Smoothed surface. Greenish colour. Brown paint. D. $23 \mathrm{~cm}$.

47. Sand temper. Smoothed surface. Buff colour. Black paint. D. $12 \mathrm{~cm}$.

48. Temper not visible. Smoothed surface. Buff colour. Brown paint. D.11 cm. 
49. Plant and lime temper. Smoothed surface. Cream colour. Black paint. D.11 cm.

50. Sand temper. Smoothed surface. Buff colour. Brown paint. D. $13 \mathrm{~cm}$.

51. Lime temper. Smoothed surface. Cream colour. Brown paint. D. $10 \mathrm{~cm}$.

52. Lime temper. Smoothed surface. Cream colour. Brown paint. D. $26 \mathrm{~cm}$.

53. Lime temper. Smoothed surface. Cream colour. Black paint.

54. Sand temper. Smoothed surface. Buff colour. Brown paint. D.16 cm.

\section{Fig. 5: Hammam IV C pottery}

55. Lime temper. Smoothed surface. Buff colour. Brown paint. D. $20 \mathrm{~cm}$.

56. Plant temper. Smoothed surface. Buff colour. Black paint. D. $19 \mathrm{~cm}$.

57. Plant and lime temper. Scraped surface. Buff colour. Brown paint. D. $11 \mathrm{~cm}$.

58. Plant and lime temper. Smoothed surface. Buff colour. Brown paint, D.10 cm.

59. Sand temper. Smoothed surface, covered by black paint. D.15 cm.

60. Lime temper. Smoothed surface. Cream colour. Brown paint. D.17 cm.

61. Sand temper. Smoothed surface. Cream colour. Brown paint. D.13 cm.

62. Sand temper. Smoothed surface. Buff colour. Brown paint. D.16 cm.

63. Lime temper. Smoothed surface. Buff colour. Black paint.

64. Sand temper. Smoothed surface. Buff colour. Black paint. D. $18 \mathrm{~cm}$.

65. Plant and lime temper. Smoothed surface. Grayish colour. Black paint. D.17 cm.

66. Sand temper. Smoothed surface. Buff colour. Black paint. D.18 cm.

67. Lime temper. Smoothed surface. Buff colour. Black paint. D.16 cm.

68. Sand temper. Smoothed surface. Buff colour. Brown paint. D.12 cm.

69. Lime temper. Smoothed surface. Cream colour. Brown paint. D.13 cm.

70. Lime temper. Smoothed surface. Buff colour. Brown paint. D.14 cm.

71. Plant and lime temper. Smoothed surface. Cream colour. Dark core. Brown paint. D.14 cm.

72. Plant and lime temper. Smoothed surface. Buff colour. Brown paint. D.21 cm.

Fig. 6: Hammam IV D (nos. 73-80) and Hammam V A pottery (nos. 81-89)

73. Lime temper. Smoothed surface. Buff colour. Dark red paint. D.17 cm.

74. Plant and lime temper. Smoothed surface. Cream colour. Brown paint. D.17 cm.

75. Plant and sand temper. Smoothed surface. Buff colour. Brown paint. D. $18 \mathrm{~cm}$.

76. Plant and lime temper. Smoothed surface. Buff colour. Brown paint. D.14 cm.

77. Lime temper. Smoothed surface. Buff colour. Brown paint. D.14 cm.

78. Sand temper. Smoothed surface. Buff colour. Reddish-brown paint. D.14 cm.

79. Plant temper. Scraped surface. Orange colour. Dark core. Black paint. D. $29 \mathrm{~cm}$.

80. Lime temper. Smoothed surface. White-cream colour. Brown paint. D.11 cm.

81. Plant and lime temper. Scraped surface. Orange colour. Dark core. Black paint. D.14 cm.

82. Plant and lime temper. Burnished surface. Buff colour. Dark core. Dark brown paint. D. $12 \mathrm{~cm}$.

83. Plant temper. Smoothed surface. White-buff colour. Dark core. Brown paint. D.18 cm.

84. Plant and lime temper. Smoothed surface. Buff colour. Brown paint. D.14 cm.

85. Plant and lime temper. Smoothed surface. Cream colour. Brown paint. D.17 cm.

86. Plant temper. Scraped surface. Buff colour. Dark core. Black paint. D. $18 \mathrm{~cm}$.

87. Plant temper. Smoothed surface. Orange colour. Dark core. Black paint. D.21 cm.

88. Plant and lime temper. Smoothed surface. Cream colour. Dark core. Brown paint.

89. Plant and lime temper. Scraped surface. Orange colour. Dark core. Black paint.

Fig. 7: Hammam IV undecorated pottery

90. Lime temper. Smoothed surface. Cream colour. D. $23 \mathrm{~cm}$.

91. Plant and lime temper. Scraped surface. Buff colour. D. $23 \mathrm{~cm}$.

92. Sand temper. Scraped surface. Orange colour. D.17 cm.

93. Lime temper. Scraped surface. Buff colour. D.17 cm.

94. Lime temper. Smoothed surface. Orange colour. D. $17 \mathrm{~cm}$.

95. Lime temper. Smoothed surface. Buff colour. D.22 cm.

96. Lime temper. Smoothed surface. Orange colour. D.16 cm. 
97. Sand temper. Smoothed surface. Buff colour. D.9 cm.

98. Lime temper. Smoothed surface. Cream colour. D. $13 \mathrm{~cm}$.

99. Lime temper. Smoothed surface. Cream colour. D.11 cm.

100. Lime temper. Smoothed surface. Buff colour. D. $10 \mathrm{~cm}$.

101. Lime temper. Smoothed surface. Buff colour. D.13 cm.

102. Sand temper. Smoothed surface. Cream colour. D. $24 \mathrm{~cm}$.

103. Sand temper. Smoothed surface. Cream colour. D. $8 \mathrm{~cm}$.

104. Sand temper. Scraped surface. Buff colour. D.7 cm.

105. Sand temper. Smoothed surface. Brown colour. D. $17 \mathrm{~cm}$.

106. Sand temper. Smoothed surface. Orange colour. D. $16 \mathrm{~cm}$.

107a. Sand temper. Smoothed surface. Orange colour. D. $15 \mathrm{~cm}$.

107b. Sand temper. Smoothed surface. Orange colour. D. $12 \mathrm{~cm}$.

108. Sand temper. Scraped surface. Buff colour. D. $15 \mathrm{~cm}$.

109. Sand temper. Smoothed surface. Buff colour. D. $15 \mathrm{~cm}$.

110. Plant and lime temper. Scraped surface. Orange colour. Dark core. D. $35 \mathrm{~cm}$.

111. Plant temper. Smoothed surface. Orange colour. Dark core. D. $23 \mathrm{~cm}$.

112. Lime temper. Smoothed surface. Orange colour. D.15 cm.

Fig. 8: Hammam V A (nos. 113-127) and Hammam V B (nos. 128-134) pottery types.

113. Plant and lime temper. Scraped surface. Orange colour. Dark core. D. $19 \mathrm{~cm}$.

114. Plant and lime temper. Scraped surface. Orange colour. Dark core. D.13 cm,

115. Plant and lime temper. Scraped surface. Orange colour. Dark core. D. $19 \mathrm{~cm}$.

116. Plant and lime temper. Scraped surface. Orange colour. Dark core. D. $24 \mathrm{~cm}$.

117. Plant and lime temper. Burnished surface. Cream colour. Dark core. D.22 cm.

118. Plant temper. Scraped surface. Orange colour. Dark core. D. $25 \mathrm{~cm}$.

119. Plant temper. Scraped surface. Orange colour. Dark core. D. $22 \mathrm{~cm}$.

120. Plant and lime temper. Scraped surface. Orange colour. Dark core. D. 25 cm.

121. Plant and lime temper. Scraped surface. Orange colour. Dark core. D. $24 \mathrm{~cm}$.

122. Plant and lime temper. Scraped surface. Orange colour. Dark core. D. $20 \mathrm{~cm}$.

123. Plant temper. Burnished surface. Reddish colour. Dark core. D. $13 \mathrm{~cm}$.

124. Plant and lime temper. Smoothed surface. Orange colour. Dark core. D. $11 \mathrm{~cm}$.

125. Plant temper. Scraped surface. Orange colour. Dark core. D.14 cm.

126. Lime temper. Scraped surface. Buff colour. Dark core. D.14 cm.

127. Lime temper. Scraped surface. Orange colour. Dark core. D.8 cm.

128. Plant temper. Scraped surface. Orange colour. Dark core. D. $25 \mathrm{~cm}$.

129. Plant and lime temper. Scraped surface. Buff colour. Dark core. D. $33 \mathrm{~cm}$.

130. Plant temper. Scraped surface. Orange colour. Dark core. D. $15 \mathrm{~cm}$.

131. Plant temper. Smoothed surface. Buff colour. D. $8 \mathrm{~cm}$.

132. Plant temper. Scraped surface. Cream colour. Dark core. D. $25 \mathrm{~cm}$.

133. Lime temper. Scraped surface. Orange colour. Dark core. D. $20 \mathrm{~cm}$.

134. Plant and sand temper. Scraped surface. Orange colour. Dark core. D. $25 \mathrm{~cm}$.

\section{Fig. 9: Hammam V B pottery}

135. Plant and lime temper. Scraped surface. Orange colour. D. $19 \mathrm{~cm}$.

136. Lime temper. Scraped surface. Orange colour. Dark core. D.21 cm.

137. Lime temper. Burnished surface. Cream colour. D. $19 \mathrm{~cm}$.

138. Plant temper. Scraped surface. Gray colour. Dark core. D. $39 \mathrm{~cm}$.

139. Plant and lime temper. Burnished surface. Gray colour. Dark core. D. $31 \mathrm{~cm}$.

140. Sand temper. Smoothed surface. Orange colour. Dark core. D. $39 \mathrm{~cm}$.

141. Lime temper. Scraped surface. Cream colour. D. $25 \mathrm{~cm}$.

142. Plant temper. Smoothed surface. Cream colour. Dark core. D. $27 \mathrm{~cm}$.

143. Calcite temper. Scraped surface. Gray colour. Dark core. D. $26 \mathrm{~cm}$.

144. Lime temper. Smoothed surface. Cream colour. Dark core. D.17 cm.

145. Lime temper. Burnished surface. Gray colour. Dark core. D.16 cm. 
146. Plant temper. Burnished surface. Gray colour. Dark core. D. $35 \mathrm{~cm}$.

147. Plant temper. Scraped surface. Orange colour. Dark core. D. $25 \mathrm{~cm}$.

148. Plant and lime temper. Scraped surface. Orange colour. Dark core. D. $34 \mathrm{~cm}$.

149. Plant and lime temper. Smoothed surface. Orange colour. Dark core. D.23 cm.

150. Plant and lime temper. Burnished surface. Gray colour. D.40 cm.

Fig. 10: Hammam V B pottery

151. Calcite temper. Smoothed surface. Gray colour. Dark core. D.25 cm.

152. Calcite temper. Smoothed surface. Gray colour. Dark core. D.27 cm.

153. Sand temper. Smoothed surface. Gray colour. Dark core. D. $22 \mathrm{~cm}$.

154. Plant temper. Scraped surface. Orange colour. Dark core. D. $33 \mathrm{~cm}$.

155. Plant temper. Scraped surface. Orange colour. Dark core. D.25 cm.

156. Plant temper. Scraped surface. Orange colour. Dark core. D. $31 \mathrm{~cm}$.

157. Plant temper. Scraped surface. White-cream colour. Dark core. D. $25 \mathrm{~cm}$.

158. Plant temper. Scraped surface. Orange colour. Dark core. D. $25 \mathrm{~cm}$.

159. Plant temper. Scraped surface. Orange colour. Dark core. D.25 cm.

160. Plant temper. Smoothed surface. Buff colour. Dark core. D. $24 \mathrm{~cm}$. 

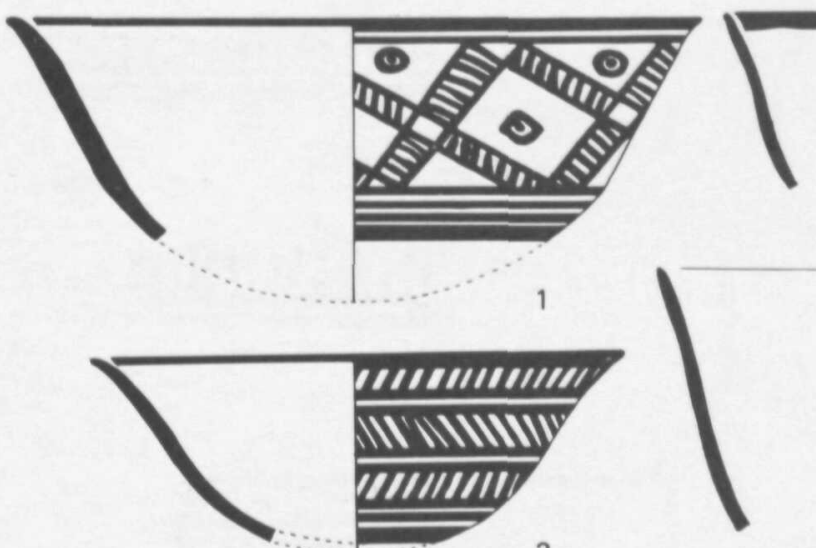

2
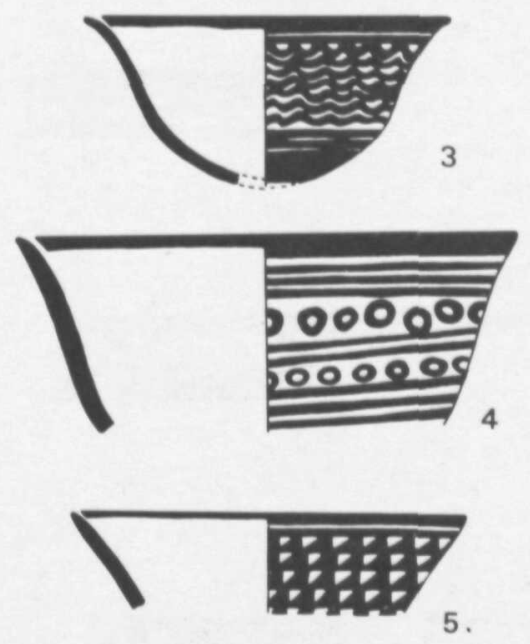

.
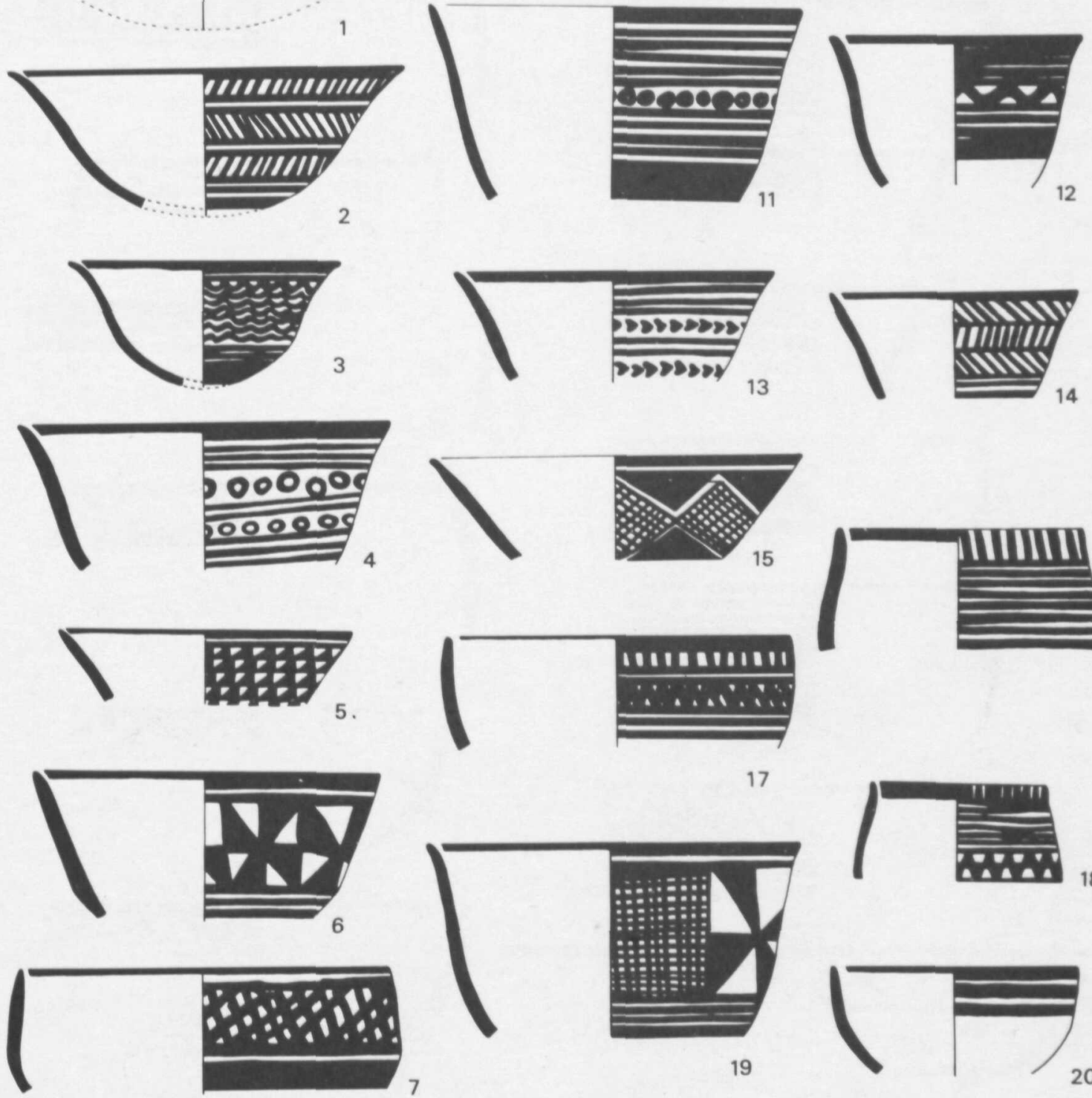

18

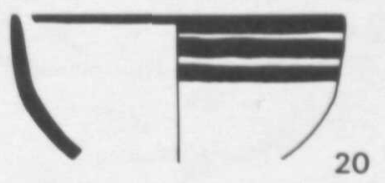

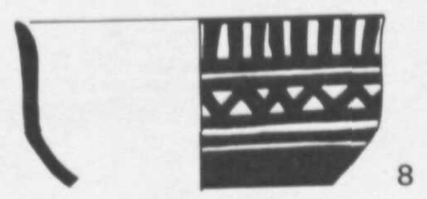
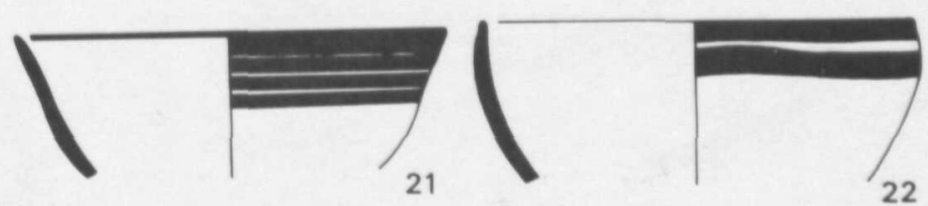

Fig. 2. Hammam IV A painted pottery (Scale $1: 3$ ). 

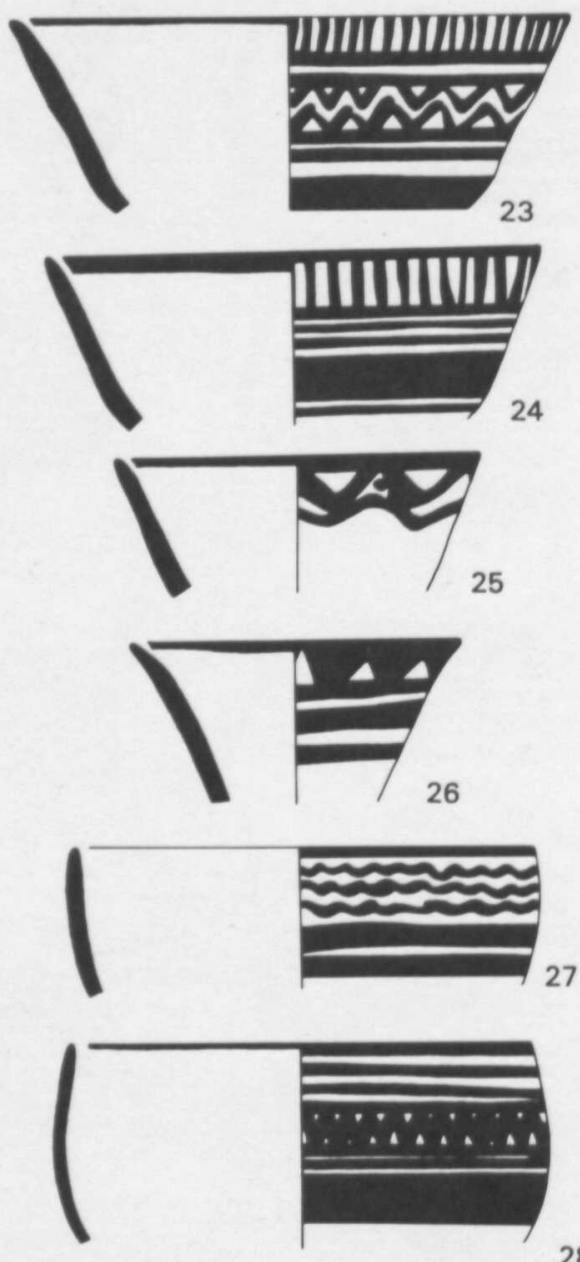

28

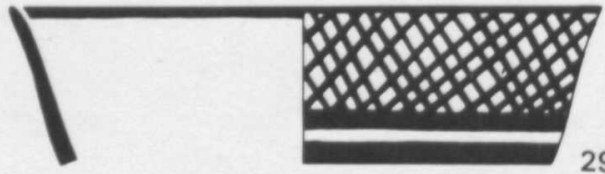

29
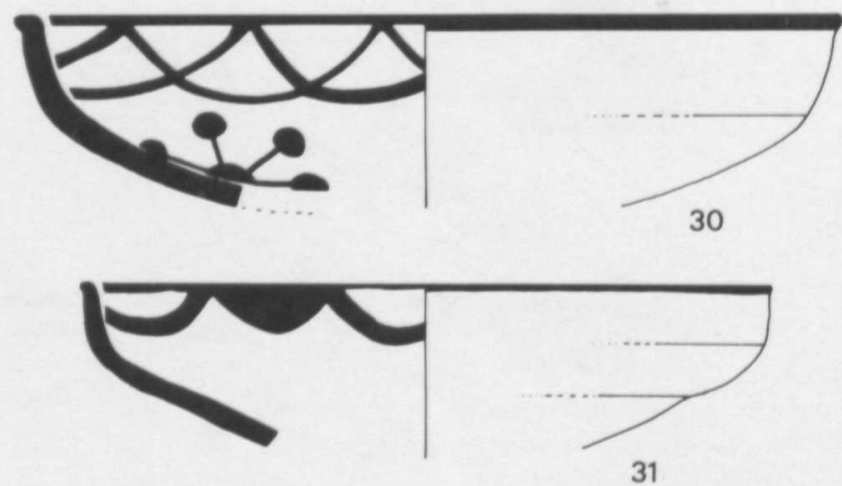

Fig. 3. Hammam IV A painted pottery (Scale $1: 3$ ).
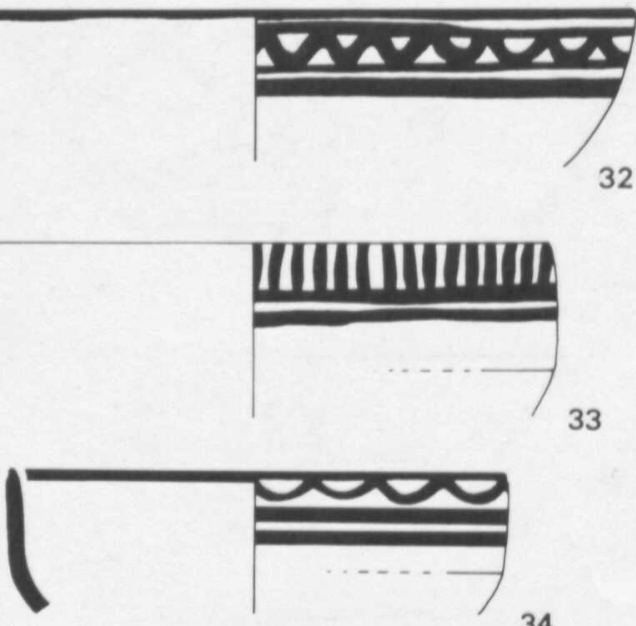

34
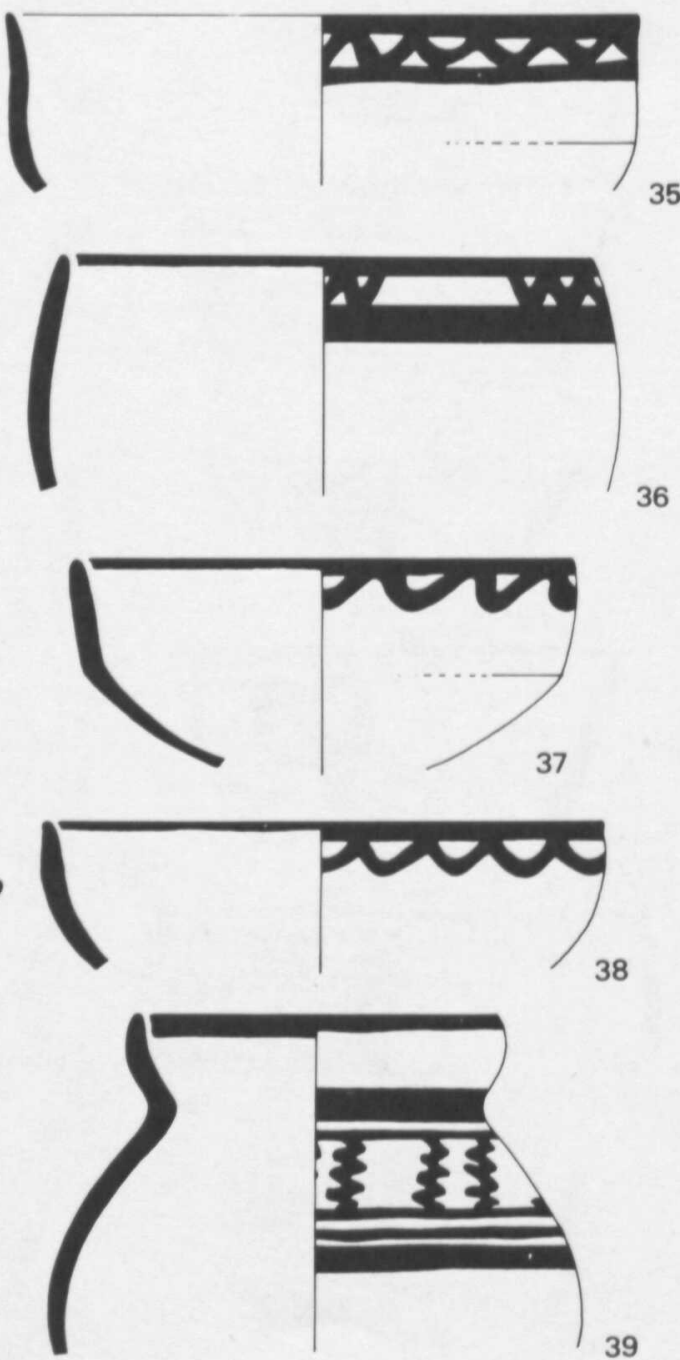

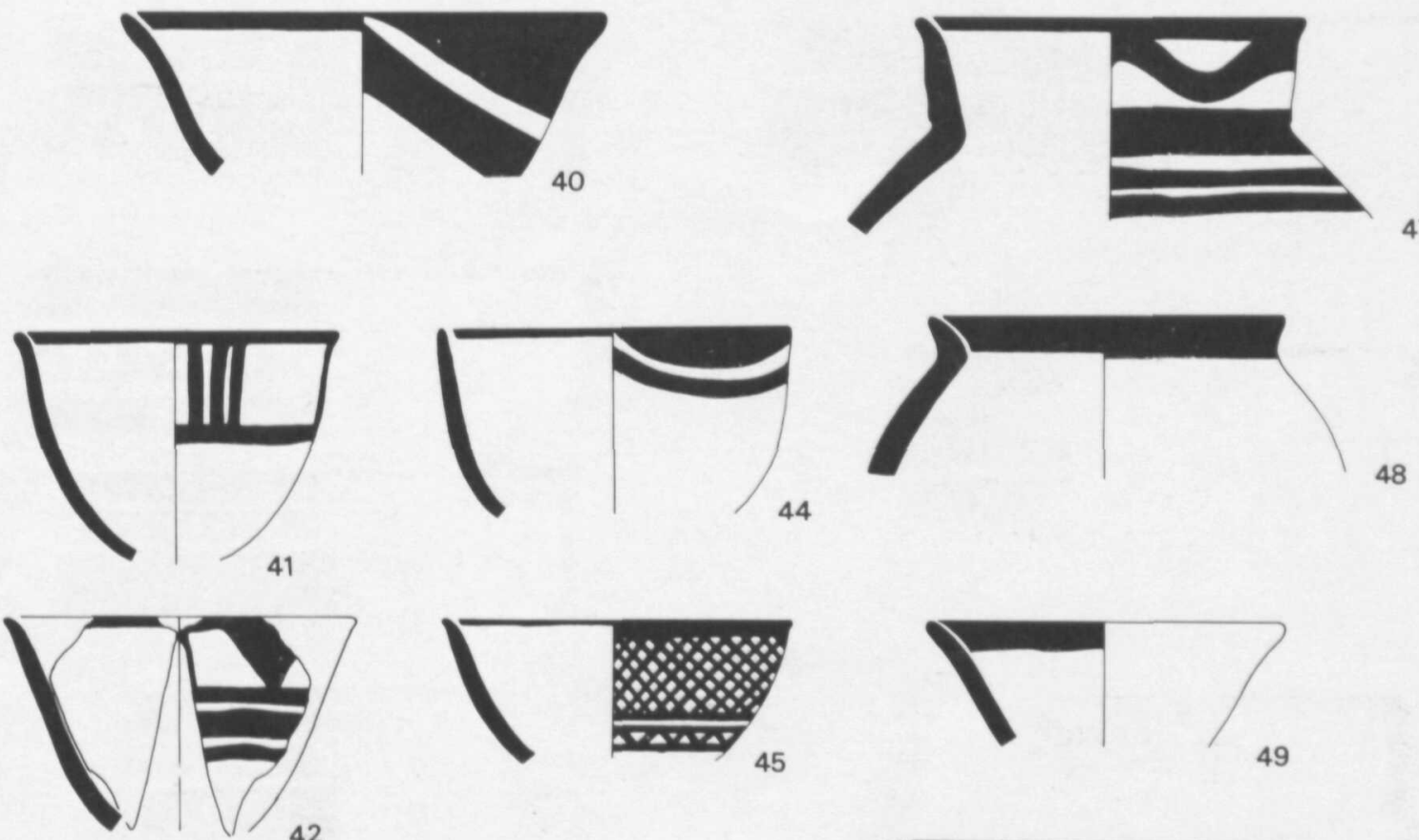

42
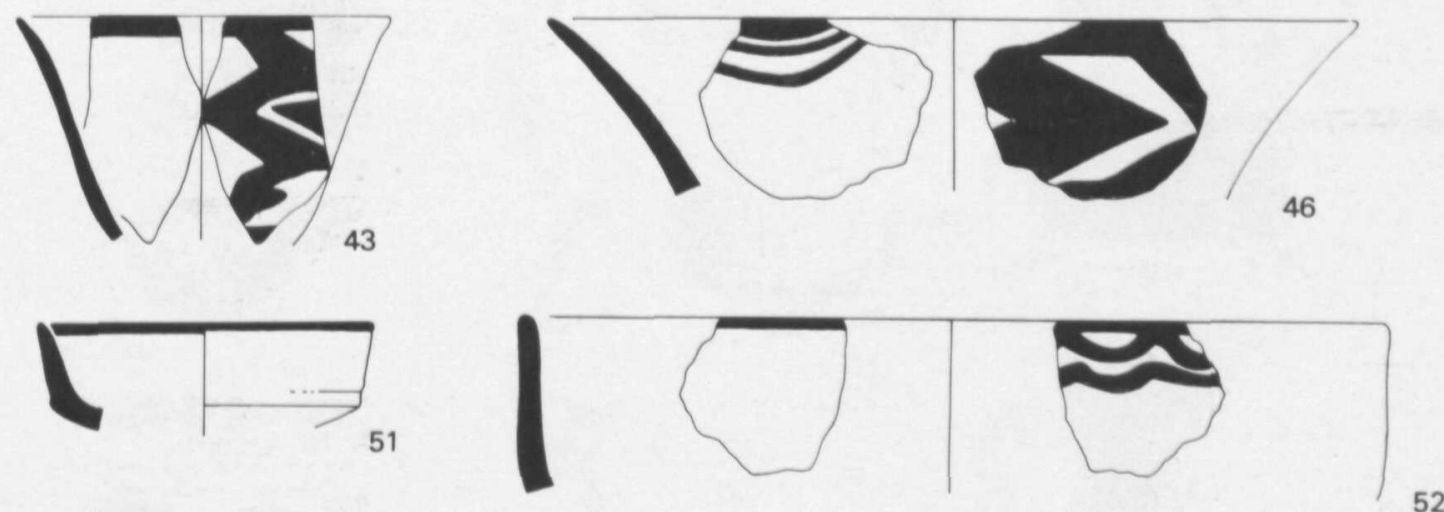

-
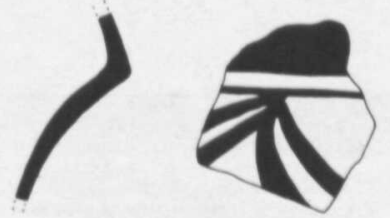

53

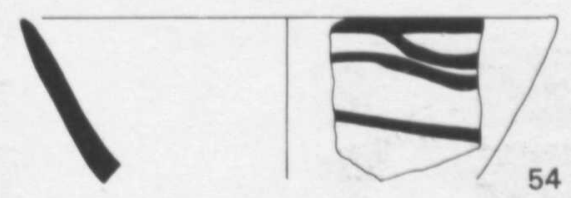

Fig. 4. Hammam IV B painted pottery (Scale $1: 3$ ). 

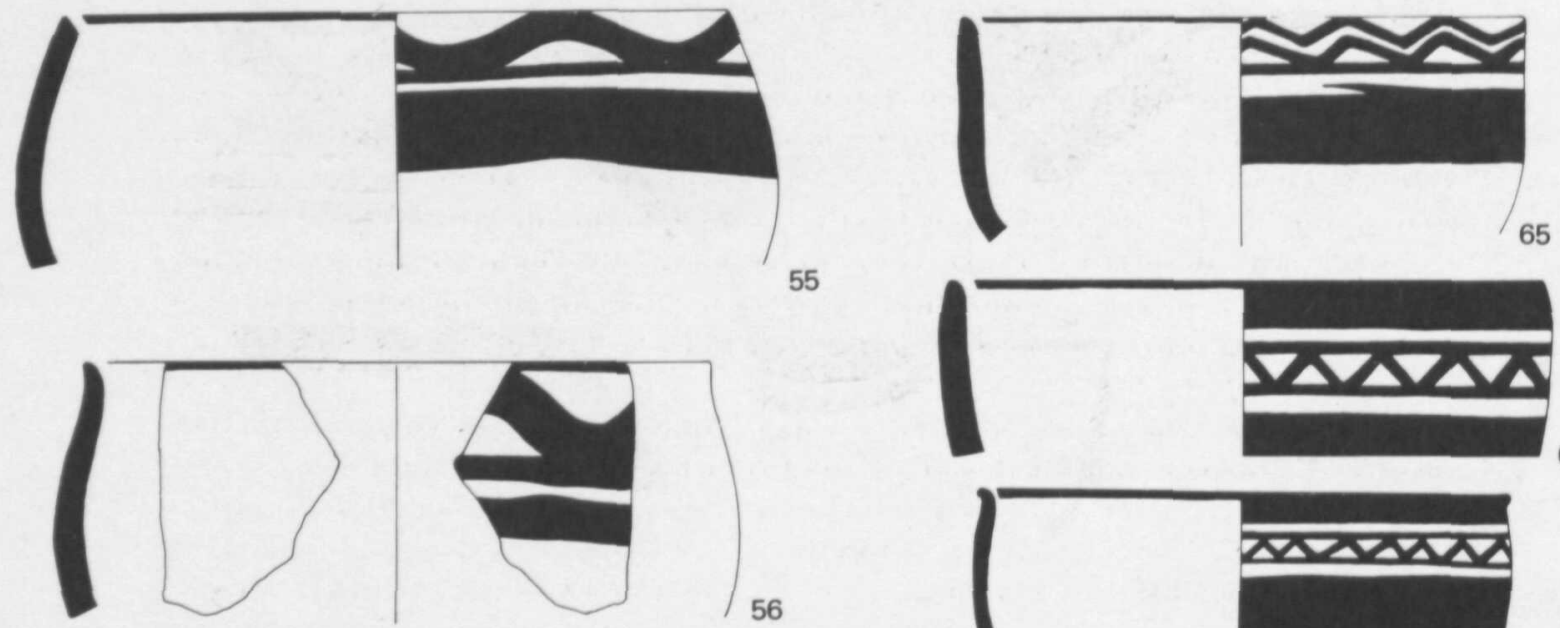

55
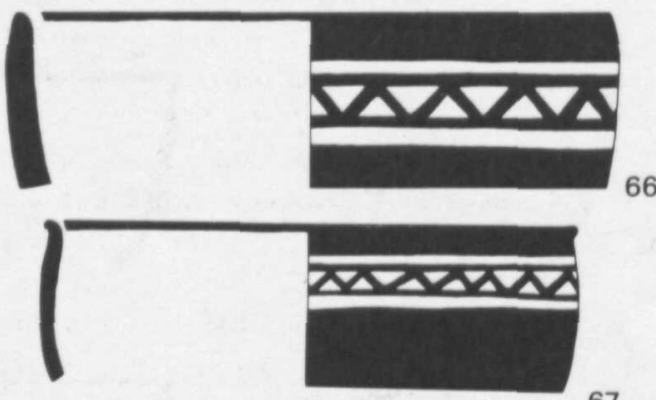

67

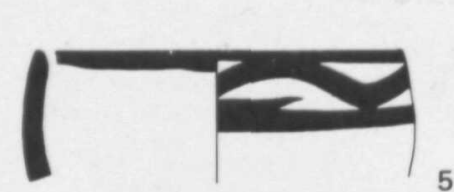

57
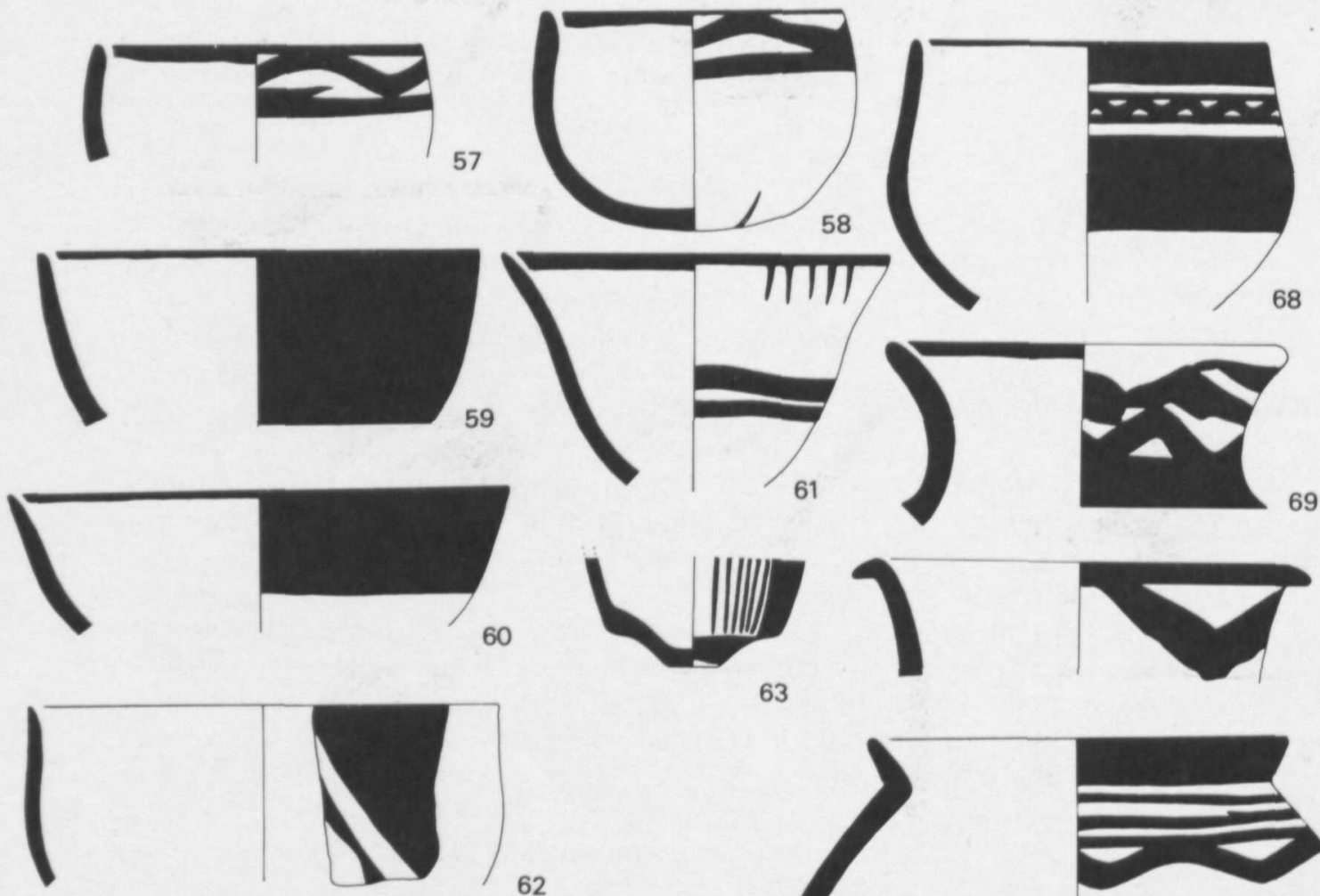

63

70
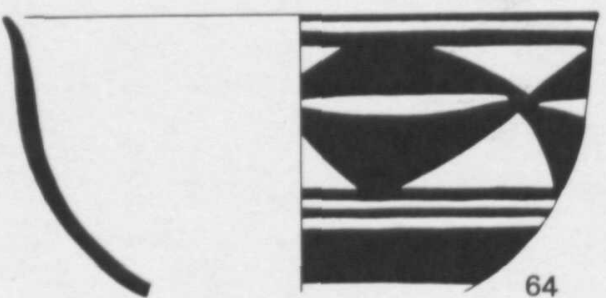

62
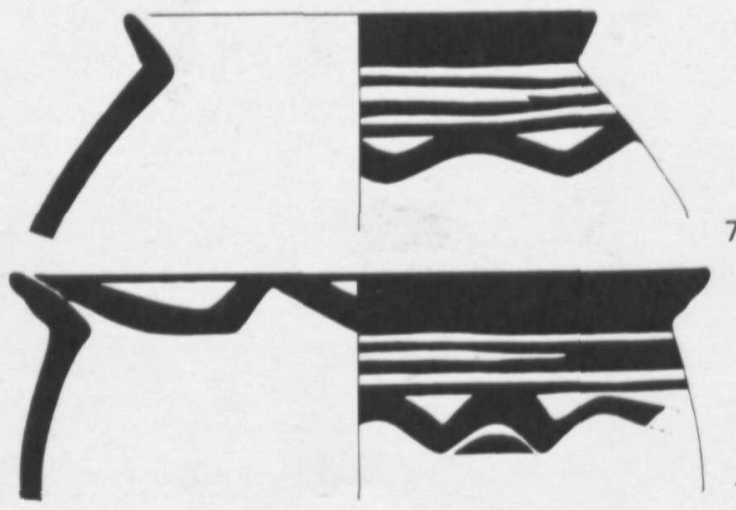

Fig. 5. Hammam IV C painted pottery (Scale 1:3). 
AN UPDATED GHRONOLOGY FOR THE NORTHERN UBAID PERIODS IN SYRIA 141
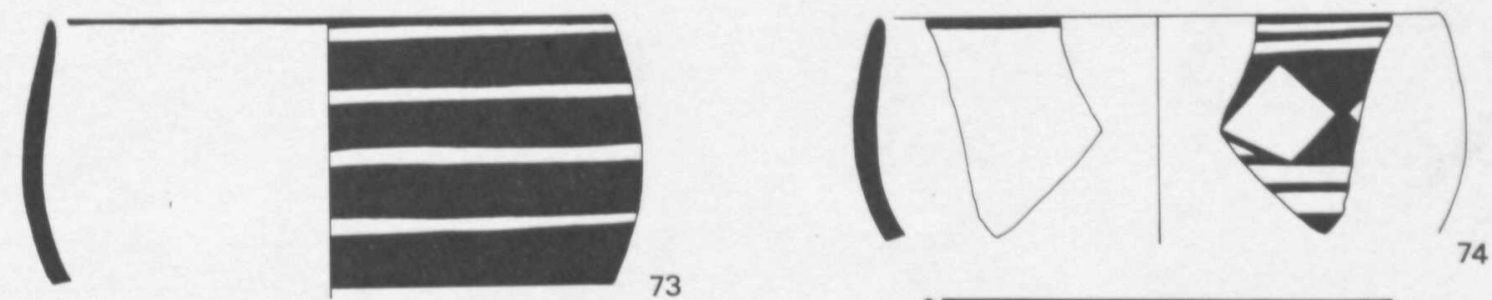

73
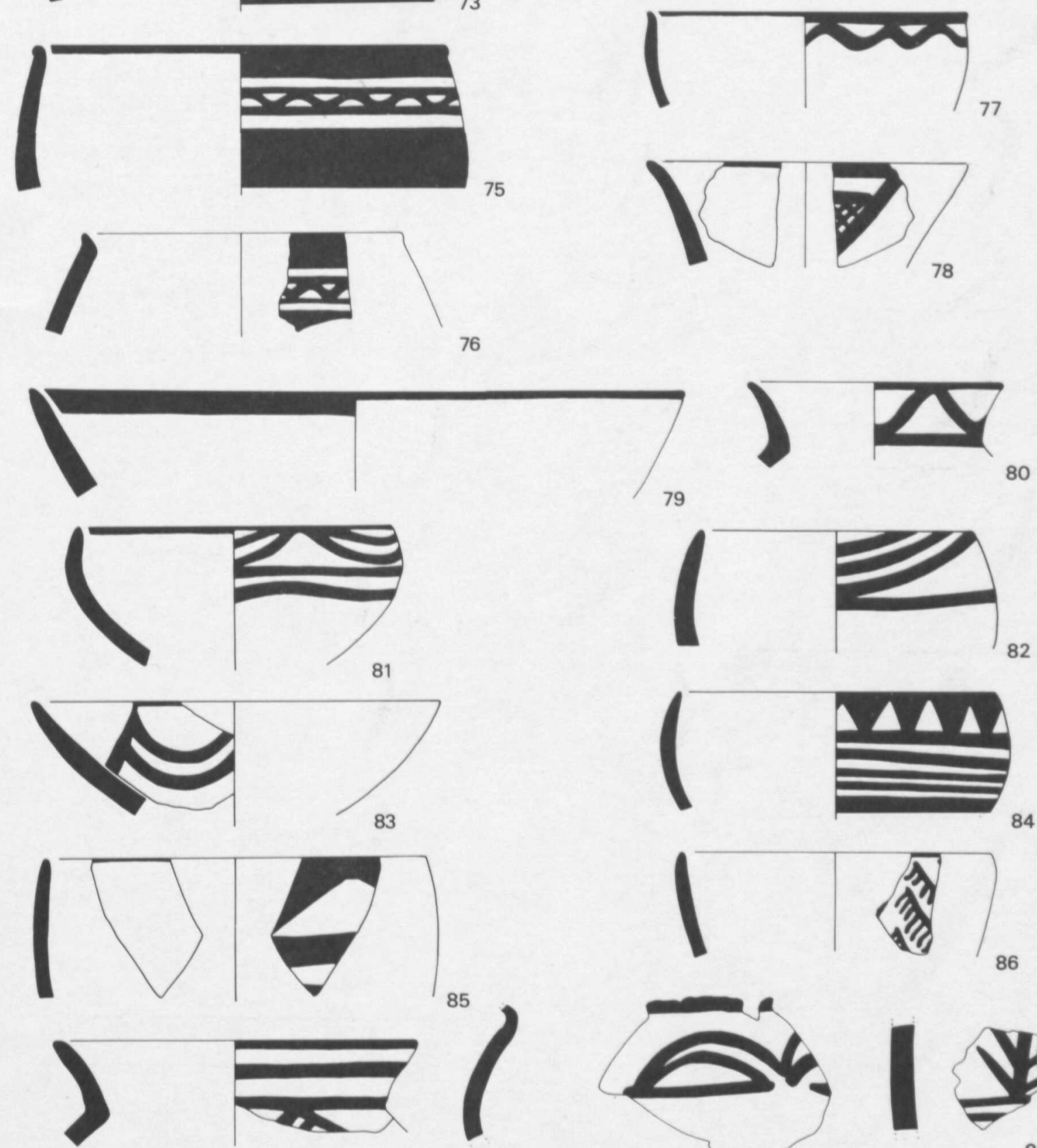

87
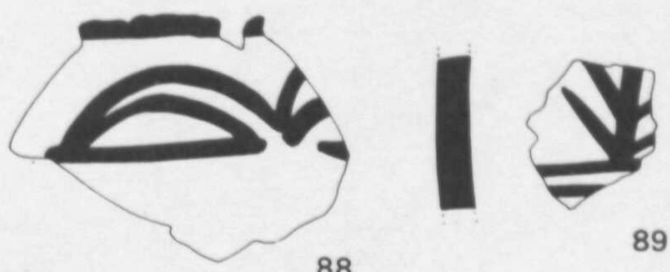

Fig. 6. Hammam IV D painted pottery (nos. 73-80) and

Hammam V A painted pottery (nos. 81-89) (Scale 1:3). 

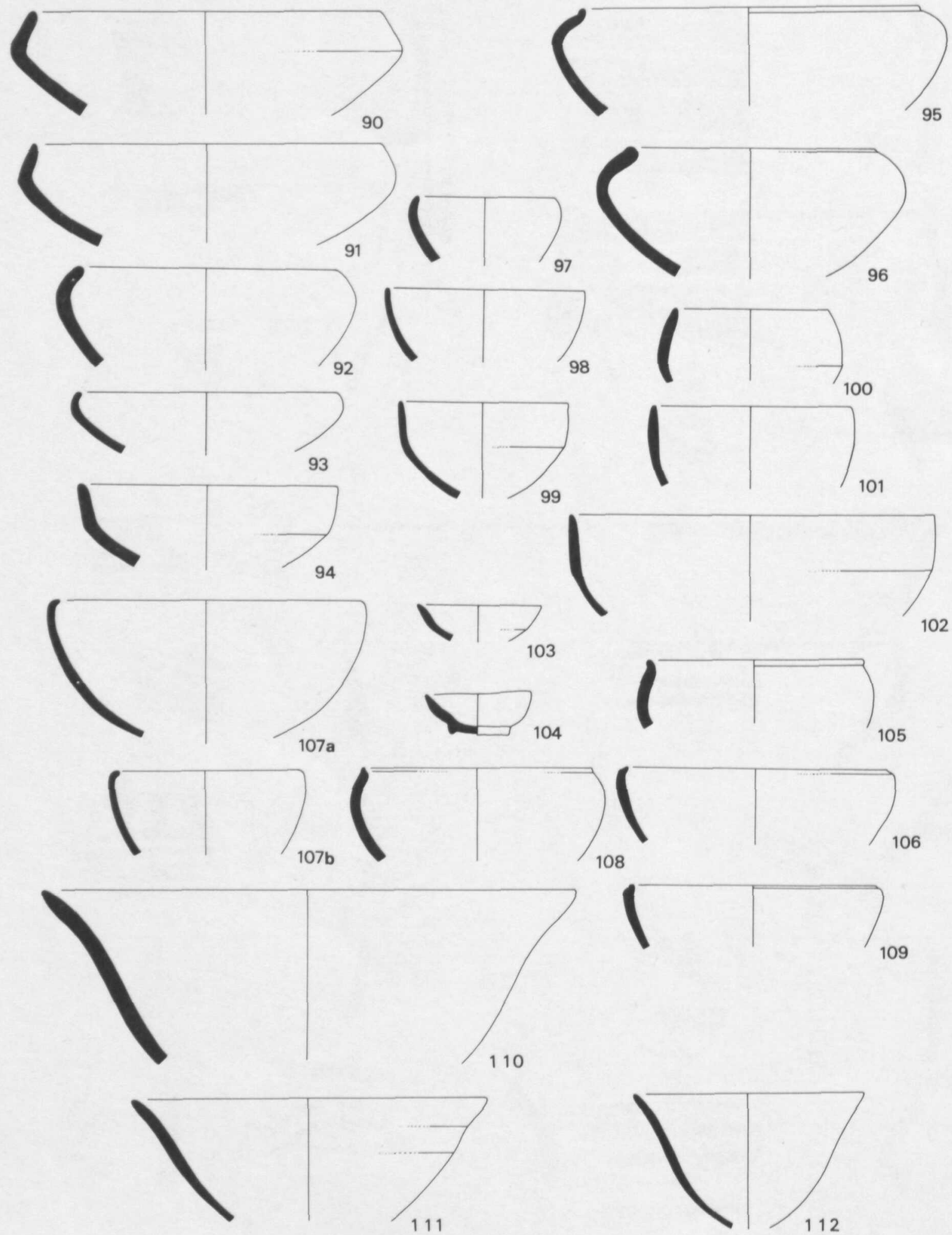

Fig. 7. Selected Hammam IV undecorated pottery (Scale $1: 3$ ). 
AN UPDATED GHRONOLOGY FOR THE NORTHERN UBAID PERIODS IN SYRIA 143
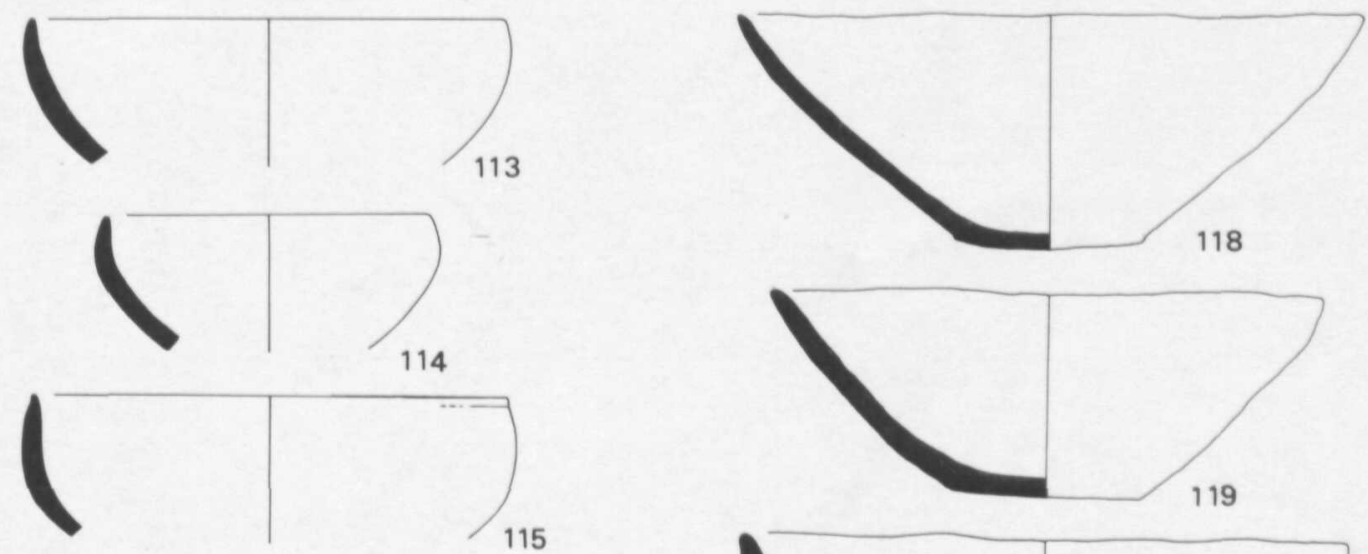

115
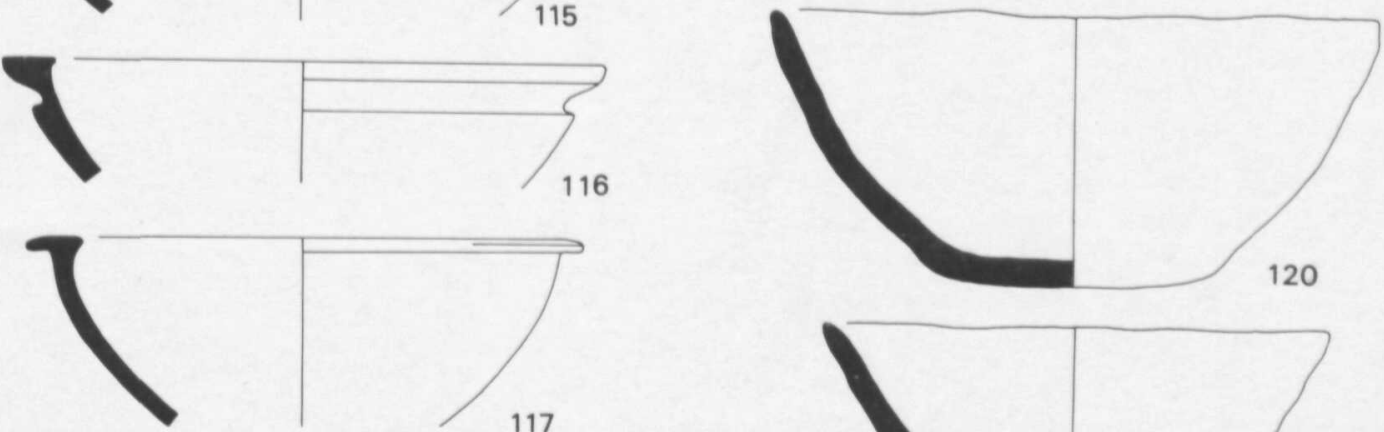

117

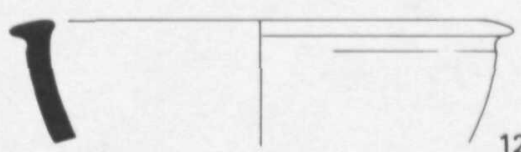

122
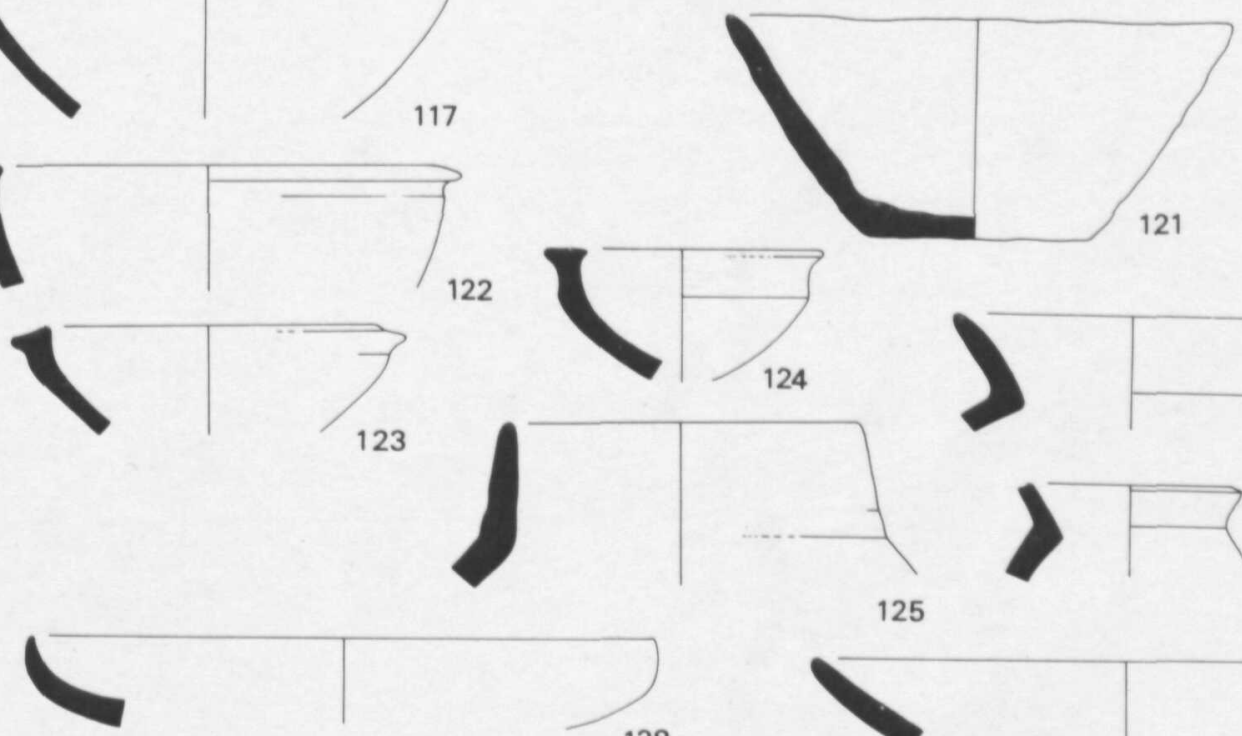

124

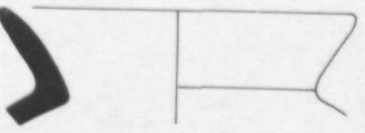

126
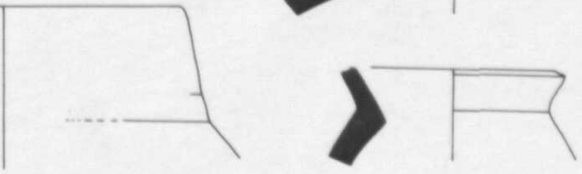

125

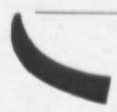

128

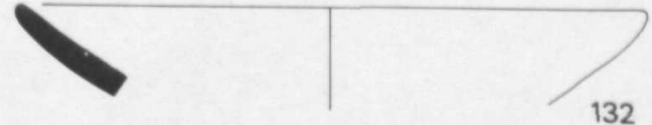

1

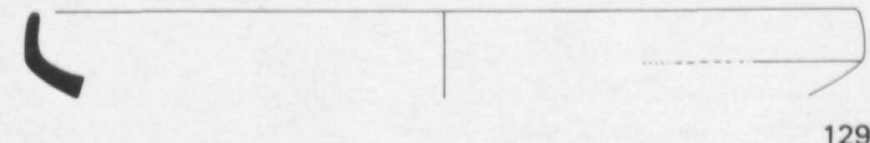

129

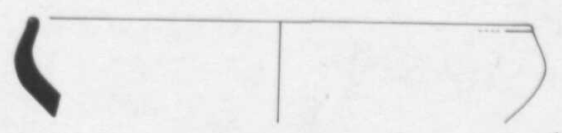

133

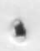
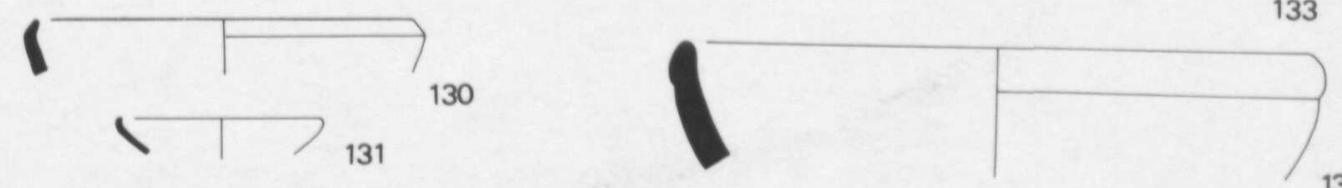

Fig. 8. Selected Hammam IV A pottery (nos. 113-127) and Hammam V B pottery (nos. 128-134) (Scale 1:3). 

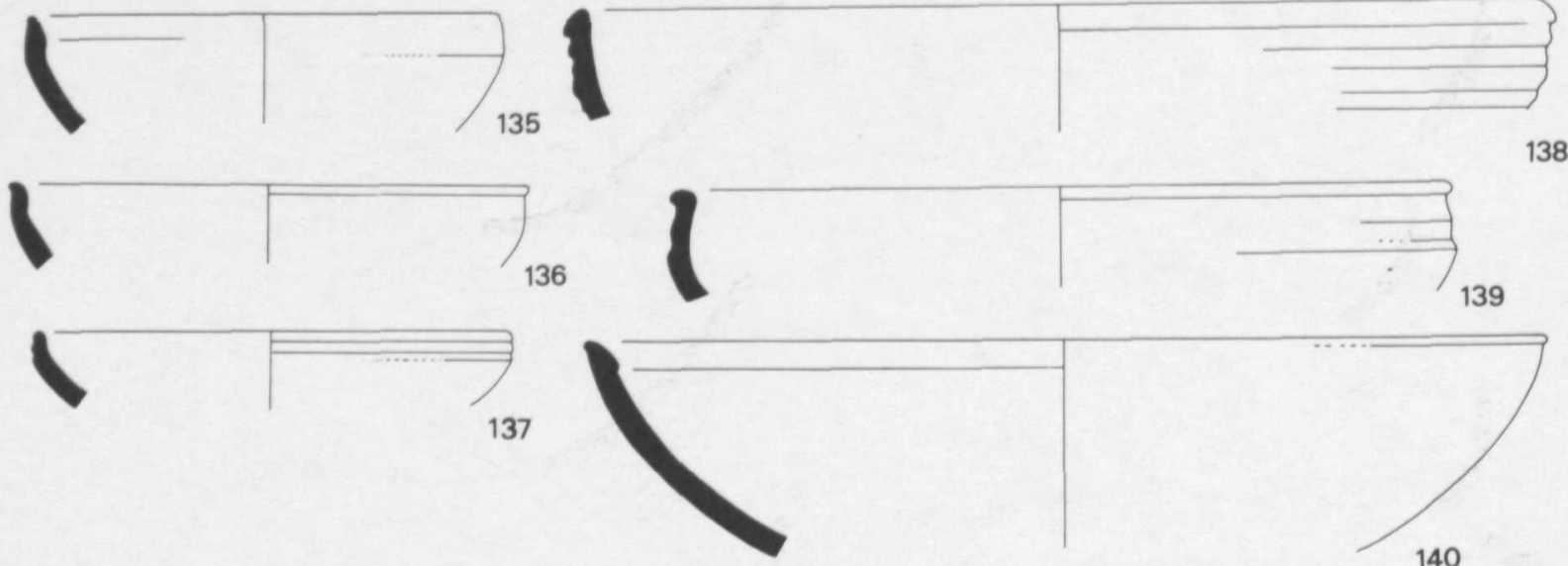

4
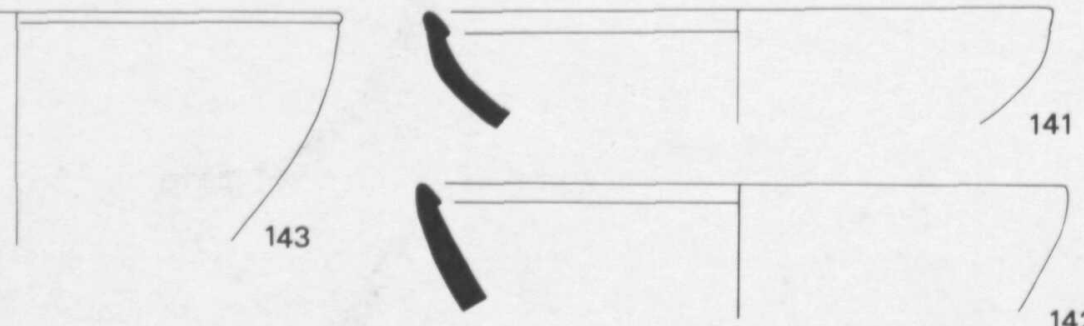

141

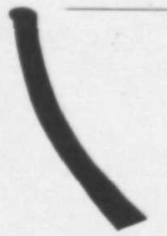

142
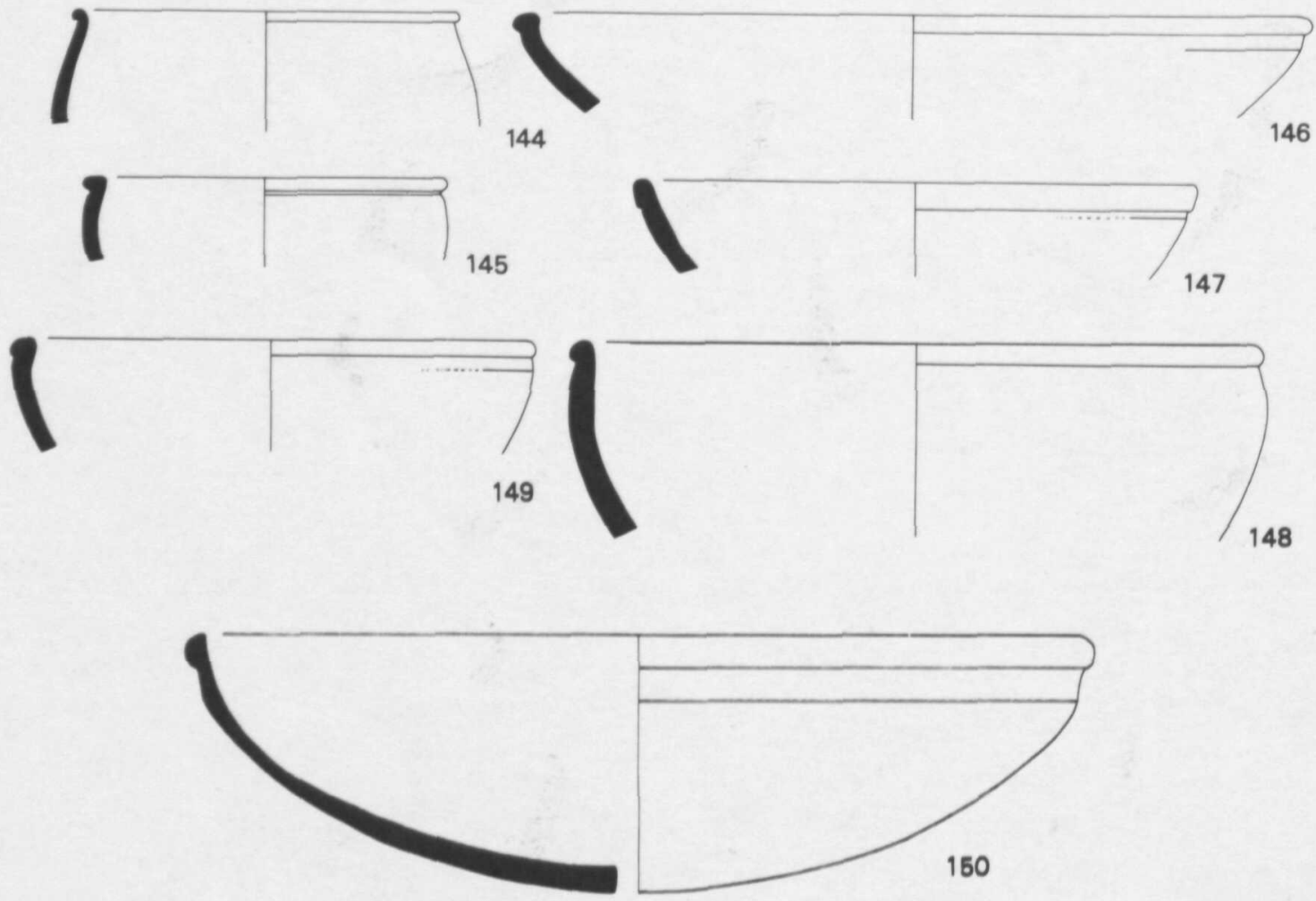

เ

Fig. 9. Selected Hammam V B pottery (Scale $1: 3$ ). 

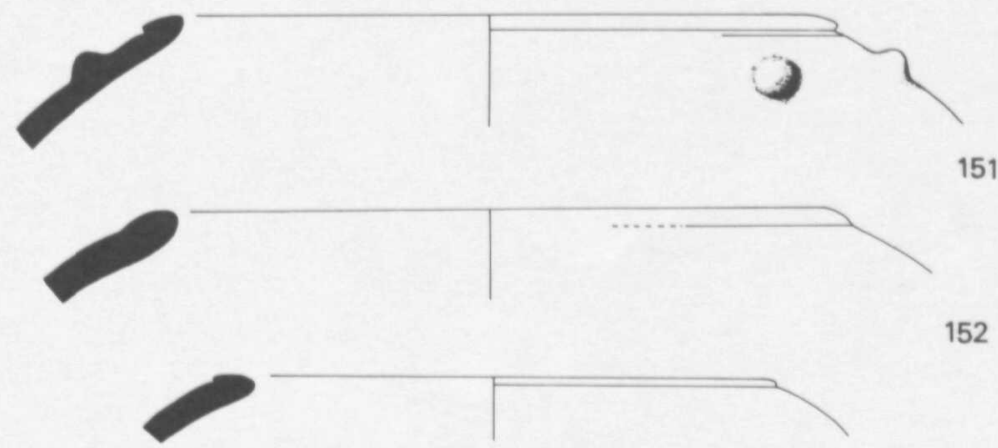

152

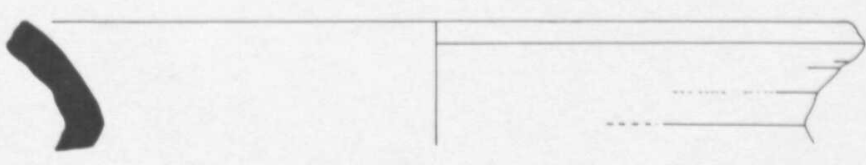

154

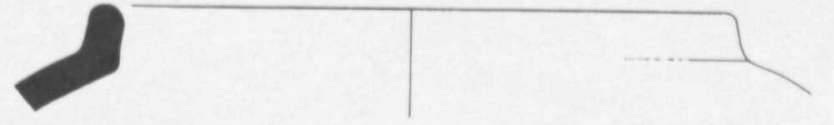

155

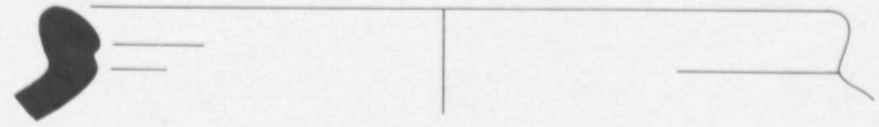

156

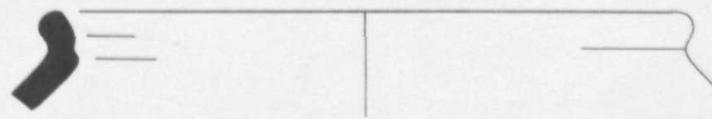

157

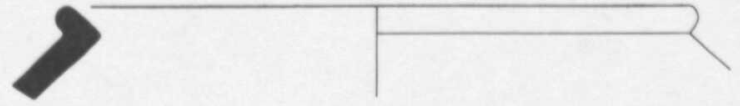

158

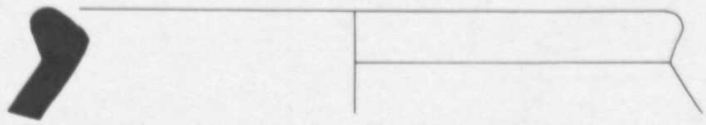

159

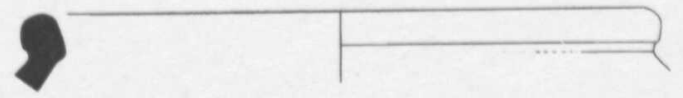

160

Fig. 10. Selected Hammam V B pottery (Scale 1:3). 